Article

\title{
Relation Between Mean Fluid Temperature and Outlet Temperature for Single U-Tube Boreholes
}

\author{
Aminhossein Jahanbin $₫$, Claudia Naldi and Enzo Zanchini * \\ Department of Industrial Engineering, Alma Mater Studiorum University of Bologna, Viale Risorgimento 2, \\ 40136 Bologna, Italy; aminhossein.jahanbin@unibo.it (A.J.); claudia.naldi2@unibo.it (C.N.) \\ * Correspondence: enzo.zanchini@unibo.it
}

Received: 20 December 2019; Accepted: 12 February 2020; Published: 14 February 2020

check for updates

\begin{abstract}
Ground-coupled heat pump (GCHP) systems usually utilize buried vertical heat exchangers, named borehole heat exchangers (BHEs). The accurate design or simulation of a GCHP system requires the calculation of the time-dependent outlet temperature from the BHEs, $T_{\text {out }}$. However, the most widely employed BHE simulation models yield the time evolution either of the mean temperature of the BHE-ground surface, $T_{s m}$, or of that of the fluid, $T_{f m}$. In transient regime, it is not easy to relate $T_{\text {out }}$ to either $T_{s m}$ or $T_{f m}$. In this paper we determine, through $3 \mathrm{D}$ finite element simulations, simple expressions of a dimensionless coefficient $\varphi$ allowing the calculation of $T_{\text {out }}$ by means of a simulation model that yields $T_{f m}$. These expressions hold for single U-tube BHEs, both in quasi-steady and in unsteady working conditions. We validate our 3D simulation code by comparison with an analytical BHE model. Then, we present applications of our expressions of $\varphi$ to calculate the time-dependent values of $T_{\text {out }}$ through a BHE model that yields those of $T_{f m}$. Finally, we show that the values of $\varphi$ in quasi-steady working conditions can be used for a simple calculation of the effective borehole thermal resistance.
\end{abstract}

Keywords: ground-coupled heat pumps; ground heat exchangers; borehole heat exchangers; single U-tube; outlet temperature; effective borehole thermal resistance

\section{Introduction}

The diffusion of ground-source heat pumps, and in particular, of ground-coupled heat pumps (GCHPs), is rapidly increasing. Indeed, GCHPs are a very efficient technology for the climatization of buildings and the production of domestic hot water [1]. The performance of these systems has been analyzed by experiments and by simulation tools [2-7]. GCHPs usually utilize buried vertical heat exchangers, named borehole heat exchangers (BHEs), that are mostly composed of a single or double polyethylene U-tube, installed in a drilled hole subsequently filled with a grouting material. A BHE has a length that commonly ranges from 50 to $200 \mathrm{~m}$, and a diameter of about $15 \mathrm{~cm}$. Improving the BHE-field design is an important way to enhance the efficiency of GCHP systems.

Several models for a BHE-field design have been proposed [8-12]. Most methods adopt dimensionless factors of thermal-response, also named $g$-functions. The $g$-function of a borefield yields the time-dependent dimensionless mean temperature of the boundary surface of the borefield caused by a constant total power released by the BHEs. Different methods to obtain the g-function of a borefield have been developed, either assuming that the heat flux released by the BHEs is uniform along the surface between BHEs and soil [13-17], or assuming that the total heat flux released by the BHEs is constant in time and the boundary between the ground and the borefield has a uniform temperature [18-21]. More accurate thermal response factors have also been determined, by assuming time-constant total heat flux and same inlet temperature in all the BHEs, and considering the influence of the borehole thermal resistance on the borefield surface temperature [22,23]. 
The $g$-functions or thermal response factors determined by the methods cited above are not precise in the short term, i.e., during the first one or two hours of operation, because the models employed do not consider accurately the thermal inertia of the BHE. Moreover, they yield the surface averaged time-dependent temperature of a borefield, $T_{s m}$, but not the time-dependent mean temperature of the fluid, $T_{f m}$. The latter is then determined by the following equation:

$$
T_{f m}-T_{s m}=q_{l m} R_{b}
$$

where $R_{b}$ is the BHE thermal resistance per unit length and $q_{l m}$ is the mean linear thermal power exchanged between the fluid and the surrounding ground. Equation (1) is correct when the heat transfer in the borehole is quasi-steady, but is not precise in the short term and yields an unphysical jump of $T_{f m}$ when $q_{l m}$ changes from zero to a given constant value.

In order to predict accurately the time evolution of $T_{f m}$ during the first hours of operation, several researchers developed simulation models that are accurate even in the short term.

De Carli et al. [24] and Zarrella et al. [25] developed a Capacity Resistance Model (CaRM) of BHE suitable for the short-term analysis and employable also in the long term. Quaggiotto el al. [26] applied the CaRM model proposed in [25] for a numerical and experimental comparison between coaxial and double U-tube BHEs. Other resistance and capacity models were presented by Bauer et al. [27] and by Pasquier and Marcotte [28]. Ruiz-Calvo et al. [29] proposed to separate the short-term and the long-term simulation and developed a short-term model based on that by Bauer et al. [27]. Li and Lai [30,31] developed a 2D analytical BHE model where the tubes are schematized as infinite line sources that supply a uniform and constant linear heat flux. Zhang et al. [32] presented a transient quasi-3D line source model that introduces the concept of transient borehole thermal resistance and gives a full-time-scale thermal response.

Beier and Smith [33] proposed an analytical cylindrical BHE model, where the borehole is represented by a grout annulus with external radius equal to that of the borehole, and internal radius such that the grout annulus has a thermal resistance equal to that of the borehole.

$\mathrm{Xu}$ and Spitler [34] developed a numerical model that approximates the real BHE structure with several concentric cylinders, that include a fluid layer, an equivalent convective-resistance layer, a tube layer, and a grout layer. Man et al. [35] presented the analytical solution for a simple cylindrical BHE model, where the thermal properties of the BHE materials coincide with those of the ground and the thermal power is supplied by a generating cylindrical surface that represents the fluid. The solution is given both for the 1D scheme, that neglects the heat conduction along the BHE axis, and for the 2D axisymmetric scheme, that takes into account the finite length of the BHE.

Bandyopadhyay et al. [36] found an analytical solution for a borehole model composed of a high-conductivity solid cylinder with heat generation, representing the fluid, and a grout layer. The solution was given in the Laplace transformed domain, and the authors employed a numerical inversion to determine the thermal response in the time domain. Javed and Claesson [37] developed a complete analytical solution of the borehole model employed by Bandyopadhyay et al. [36]. Claesson and Javed [38] proposed an analytical method to determine the thermal response of a borehole, valid both in the short term and in the long term, by coupling the short-term model presented in Javed and Claesson [37] to a long-term model based on the finite line-source solution.

Beier [39] developed an analytical BHE model that approximates the U-tube as two half tubes, and considers both the fluid and the grout thermal capacity. The analytical solution is given in the Laplace transformed domain and is inverted by using the Stehfest algorithm. Lamarche [40] developed an analytical cylindrical borehole model in which the borehole is composed of a solid cylinder subjected to heat generation, representing the fluid, surrounded by cylindrical layers representing the polyethylene pipes, and the grout. Naldi and Zanchini [41] proposed a numerical BHE model (OMEC) composed of a homogeneous equivalent cylinder having an internal heat-generating surface and thermal properties suitable to reproduce both the thermal resistance and the heat capacity of the BHE. By means of that 
model, the authors determined the full-time-scale evolution of $T_{f m}$ for a borefield with BHEs having equal inlet temperatures.

Most of the short-term or full-time-scale simulation models cited above yield directly the time evolution of $T_{f m}$, for a borefield subjected to a time constant heat load, without employing Equation (1). However, they do not yield directly the time evolution of the outlet fluid temperature, $T_{\text {out }}$, that is needed for the simulation of the heat pump. Therefore, it is interesting to complete these models by providing relations between $T_{f m}$ and $T_{\text {out }}$.

Beier and Spitler [42] presented a method that allows determining the dimensionless factor $f$, given by:

$$
f T_{\text {in }}+(1-f) T_{\text {out }}=T_{\text {fm }}
$$

where $T_{\text {in }}$ is the inlet fluid temperature. Equation (2) and the energy balance equation:

$$
T_{\text {in }}-T_{\text {out }}=\frac{\dot{Q}}{\dot{m} c_{p}}
$$

where $\dot{Q}$ is the thermal power supplied by the heat pump to the borehole fluid, $\dot{m}$ and $c_{p}$ are the mass flow rate and specific heat capacity of the fluid, yield:

$$
T_{\text {out }}=T_{f m}-f \frac{\dot{Q}}{\dot{m} c_{p}}
$$

Through 3D finite element simulations and best fit of simulation results, Zanchini and Jahanbin [43] determined simple correlations to evaluate the dimensionless coefficient $\varphi$ defined as:

$$
\varphi=\frac{\dot{V}}{\dot{V}_{0}} \frac{T_{\text {ave }}-T_{\text {fm }}}{T_{\text {in }}-T_{\text {out }}}
$$

where $\dot{V}$ is the volume flow rate, $\dot{V}_{0}$ is a reference value of $\dot{V}$, namely $12 \mathrm{~L}$ per minute $(\mathrm{L} / \mathrm{min})$, and $T_{\text {ave }}$ $=\left(T_{\text {in }}+T_{\text {out }}\right) / 2$. The correlations reported in [43] apply to double U-tube boreholes. Equation (5) and the balance Equation (3) yield:

$$
T_{\text {out }}=T_{f m}-\left(0.5-\varphi \frac{\dot{V}_{0}}{\dot{V}}\right) \frac{\dot{Q}}{\dot{m} c_{p}} .
$$

In the present paper, new correlations to determine $\varphi$ are provided, for single $U$ tube BHEs, through the best fit of the results of 3D numerical simulations. These correlations can be employed to obtain an accurate evaluation of the time evolution of $T_{\text {out }}$ by means of a BHE simulation code that yields the time evolution of $T_{f m}$. An example of this use is reported, in the case of constant flow rate and constant power supplied to the ground, by evaluating the time evolution of $T_{f m}$ through the simple analytical BHE model proposed by Man et al. [35], and that of $T_{\text {out }}$ through Equation (6). Then it is shown that our correlations for $\varphi$ can be applied to determine accurately the time evolution of $T_{\text {out }}$ from that of $T_{f m}$ even in the simulation of BHE fields subjected to a time dependent heat load. Finally, it is shown that the correlation for $\varphi$ valid for the quasi-stationary regime can be employed for an immediate calculation of the effective BHE thermal resistance.

\section{Simulation Cases and Method}

We considered nine BHE geometries, with BHE diameter $D_{b}=152 \mathrm{~mm}$, shank spacing $d=84,94$ and $104 \mathrm{~mm}$, length $L=50,100$ and $200 \mathrm{~m}$, pipes with internal diameter $D_{p i}=32.6 \mathrm{~mm}$ and external diameter $D_{p e}=40 \mathrm{~mm}$. Sketches of the BHE cross sections considered are illustrated in Figure 1 . 


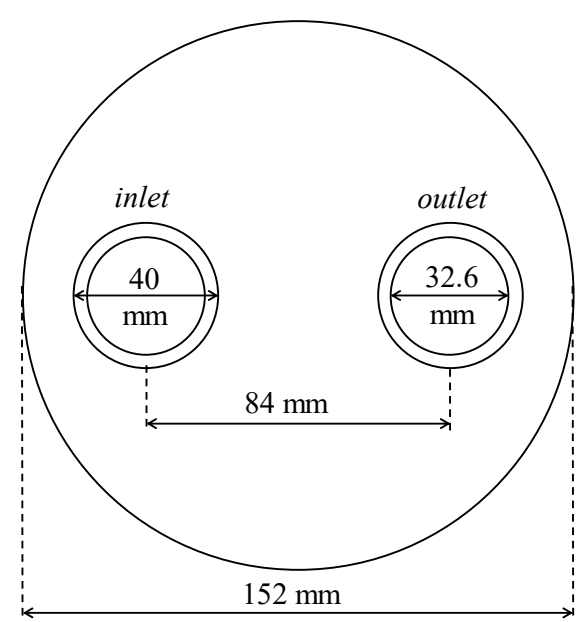

(a)

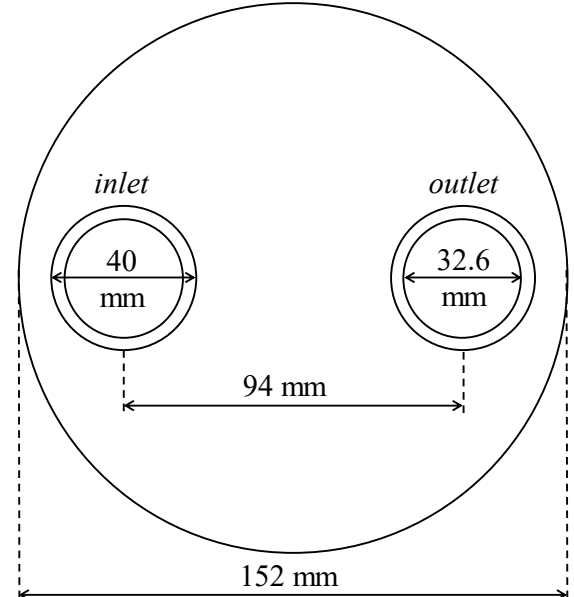

(b)

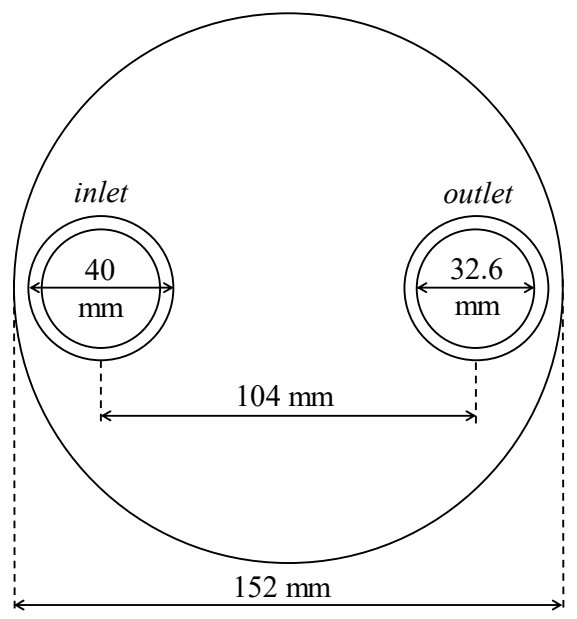

(c)

Figure 1. Sketches of the BHE cross sections considered, with shank spacing $84 \mathrm{~mm}(\mathbf{a}), 94 \mathrm{~mm}(\mathbf{b})$ and $104 \mathrm{~mm}(\mathrm{c})$.

For each geometry, we considered three grout thermal conductivities, 1.0, 1.6 and $2.3 \mathrm{~W} /(\mathrm{mK})$, two flow rates, $\dot{V}=12$ and $24 \mathrm{~L} / \mathrm{min}$, and ground thermal conductivity $k_{g}=1.8 \mathrm{~W} /(\mathrm{mK})$ (typical value). The following values were adopted for the thermal properties nearly uninfluential on $\varphi$ : polyethylene thermal conductivity and volumetric heat capacity $k_{p}=0.4 \mathrm{~W} /(\mathrm{mK})$ and $(\rho c)_{p}=1.824 \mathrm{MJ} /\left(\mathrm{m}^{3} \mathrm{~K}\right)$; grout and ground volumetric heat capacities $(\rho c)_{g t}=1.600 \mathrm{MJ} /\left(\mathrm{m}^{3} \mathrm{~K}\right)$ and $(\rho c)_{g}=2.500 \mathrm{MJ} /\left(\mathrm{m}^{3} \mathrm{~K}\right)$. We examined the cooling operation, with inlet fluid temperature $32^{\circ} \mathrm{C}$. Thus, 54 finite element simulations were performed to determine the correlations for $\varphi$. Additional simulations were performed to validate the simulation code, as well as to check the validity of the correlations for other values of $D_{b}$ and of $k_{g}$ and for other working conditions.

Water has been considered as working fluid. The water thermal properties at $T_{\text {in }}$ have been taken from NIST [44]: density $\rho_{w}=995.03 \mathrm{~kg} / \mathrm{m}^{3}$, dynamic viscosity $\mu_{w}=0.76456 \mathrm{mPa}$, specific heat capacity $c_{p w}=4179.5 \mathrm{~J} /(\mathrm{kg} \mathrm{K})$, thermal conductivity $k_{w}=0.61869 \mathrm{~W} /(\mathrm{mK})$. The water velocity was considered vertical and uniform. A heat flux per unit area given by the product of the convection coefficient and the temperature difference between fluid and solid surface was applied at the fluid-solid interface. The Reynolds, Nusselt and Prandtl numbers, and the heat transfer coefficient $h$ are given in Table 1 . The Nusselt number was calculated through the Churchill correlation with uniform wall heat flux [45]. 
Table 1. Values of $\dot{V}$, of $R e, P r$, and $N u$ numbers, and of the convection coefficient.

\begin{tabular}{ccccc}
\hline$\dot{V}(\mathrm{~L} / \mathbf{m i n})$ & $\boldsymbol{R} \boldsymbol{P r}$ & $\boldsymbol{N u}$ & $\boldsymbol{h}\left(\mathrm{W} /\left(\mathrm{m}^{\mathbf{2}} \mathbf{K}\right)\right)$ \\
\hline 12 & 10,166 & 5.16 & 77.1 & 1462.2 \\
24 & 20,332 & 5.16 & 135.5 & 2571.4 \\
\hline
\end{tabular}

The ground surrounding the borehole has been represented as a cylinder coaxial with the borehole, having radius $10 \mathrm{~m}$ and $10 \mathrm{~m}$ longer than the BHE. The initial temperature of the ground and of the BHE has been set equal to the undisturbed ground temperature, $T_{g}$. The latter has been supposed equal to $14{ }^{\circ} \mathrm{C}$ for $z=10 \mathrm{~m}$, with geothermal gradient $0.03{ }^{\circ} \mathrm{C} / \mathrm{m}$ for $z>10 \mathrm{~m}$. The following distribution of $T_{g}(z)$ has been assumed for $z<10 \mathrm{~m}$ :

$$
T_{g}(z)=e^{-z} \times\left[T_{g}(0)-T_{g}(10)\right]+T_{g}(10), \quad T_{g}(0)=24^{\circ} \mathrm{C} .
$$

An adiabatic boundary condition has been imposed at the lateral and bottom ground surfaces and at the top of the borehole. The boundary condition $T_{g}(0)=24{ }^{\circ} \mathrm{C}$ has been applied at the horizontal ground surface.

Numerical simulations for a working period of $100 \mathrm{~h}$ have been carried out by a 3D finite element model, through COMSOL Multiphysics. The working period selected is more than sufficient to reach a quasi-stationary heat transfer regime in the BHE and to obtain abundant data of $\varphi$ in this regime.

The reduced vertical coordinate $\widetilde{z}=z / c$ has been introduced to shorten the computational domain along $z$ [46]. Consequently, a reduced thermal conductivity along $z, \widetilde{k}_{z}=k_{z} / c^{2}$, has been employed for every material; in addition, a reduced vertical water velocity $\widetilde{w}=w / c$ has been assumed. A more detailed description of the method can be found in Refs. [43,46]. The reduction coefficient $c$ has been taken equal to 5 for BHEs with length $50 \mathrm{~m}$, equal to 10 for BHEs with length $100 \mathrm{~m}$, and equal to 20 for BHEs with length $200 \mathrm{~m}$.

In COMSOL Multiphysics, the time steps are non-uniform and are optimized by the software so that the solution matches the accuracy parameters imposed by the user. We have selected absolute tolerance 0.0001 and relative tolerance 0.001 , instead of the default values 0.001 and 0.01 , respectively.

For each geometry, the computational domain has been meshed with unstructured tetrahedral elements. Due to the rescaling coefficient, the selected mesh, illustrated in Figure 2, is independent of the BHE length, and has 1,369,572 elements for $d=84 \mathrm{~mm}, 1,444,394$ elements for $d=94 \mathrm{~mm}$, and $1,510,647$ elements for $d=104 \mathrm{~mm}$.

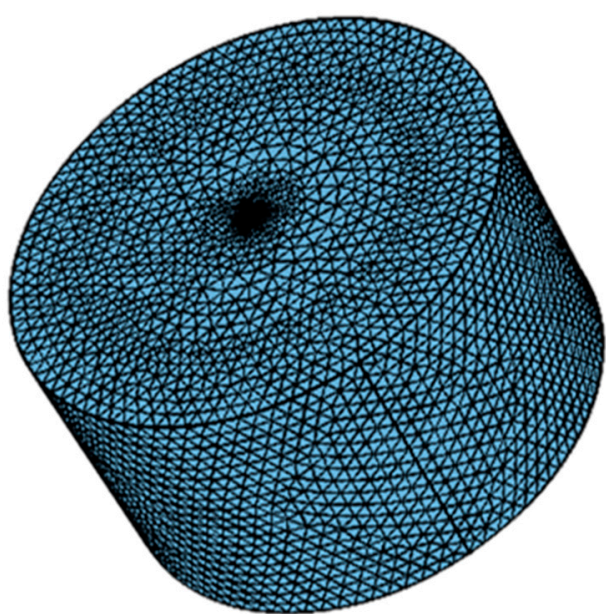

(a)

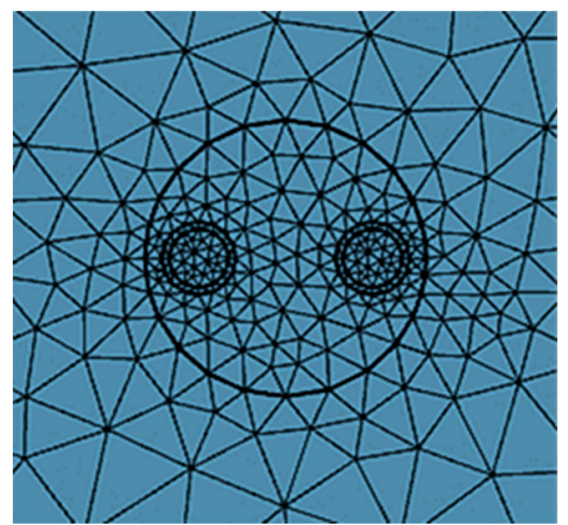

(b)

Figure 2. Illustration of the mesh employed for $d=94 \mathrm{~mm}(\mathbf{a})$, and particular of the borehole top (b). 
In order to ensure that the results are mesh independent, simulations have been carried out by employing meshes with 1,198,027,1,311,663 and 1,444,394 tetrahedral elements, for $L=100 \mathrm{~m}, d=$ $94 \mathrm{~mm}, k_{g t}=1.6 \mathrm{~W} /(\mathrm{mK}), k_{g}=1.8 \mathrm{~W} /(\mathrm{mK})$, and $\dot{V}=12 \mathrm{~L} / \mathrm{min}$. The values of $T_{\text {ave }}-T_{f m}$ determined at $\tau=2 \mathrm{~h}, 20 \mathrm{~h}$ and $100 \mathrm{~h}$ from the operation start have been compared, and the maximum percent deviation from the values obtained with the third mesh, employed in the final simulations, has been $0.127 \%$.

\section{Correlations for $\varphi$}

The correlations for $\varphi$ have been determined first for the quasi-stationary regime within the BHE, and then for the transient regime.

\subsection{Quasi-Stationary Regime}

The simulation results revealed that, after $2 \mathrm{~h}$ of operation with constant $T_{\text {in }}$ and $\dot{V}$, the quantity $T_{\text {ave }}-T_{f m}$ becomes a homogeneous linear function of $\left(T_{\text {in }}-T_{\text {out }}\right) / \dot{V}$ that depends only on $L, d$, and $k_{g t}$. Thus, a homogeneous linear regression of $T_{\text {ave }}-T_{f m}$ as a function of $\left(T_{\text {in }}-T_{\text {out }}\right) / \dot{V}$ has been determined for each BHE geometry and for each value of $k_{g t}$, by employing the simulation results for $\tau$ $\geq 2 \mathrm{~h}$. The angular coefficient of each expression, divided by $\dot{V}_{0}=12 \mathrm{~L} / \mathrm{min}$, gives a value of $\varphi$ for the quasi-stationary regime, denoted by $\varphi_{\infty}$. The linear regressions obtained for $L=100 \mathrm{~m}$ and $d=94 \mathrm{~mm}$ are illustrated, as an example, in Figure 3. The values of $\varphi_{\infty}$ are reported in Table 2.

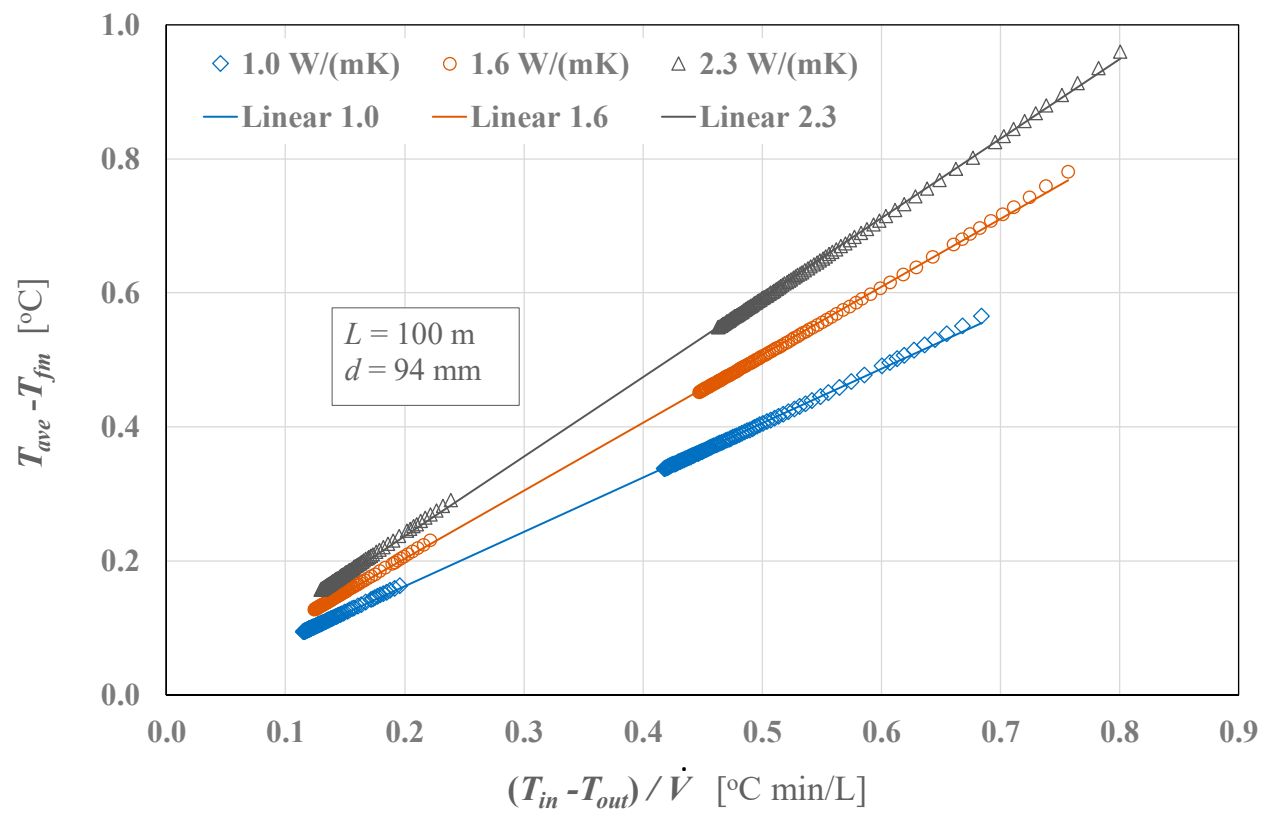

Figure 3. Linear regressions of $T_{\text {ave }}-T_{f m}$ as a function of $\left(T_{\text {in }}-T_{\text {out }}\right) / \dot{V}$, for $L=100 \mathrm{~m}, d=94 \mathrm{~mm}, k_{g t}$ $=1.0,1.6$ and $2.3 \mathrm{~W} /(\mathrm{mK})$.

In order to determine a correlation for $\varphi_{\infty}$, the following dimensionless quantities have been employed:

$$
\begin{gathered}
L^{*}=L / L_{0}, \\
k^{*}=k_{g t} / k_{g t 0}, \\
d^{*}=d / d_{0},
\end{gathered}
$$


where $L_{0}=100 \mathrm{~m}, k_{g t 0}=1.6 \mathrm{~W} /(\mathrm{mK})$, and $d_{0}=94 \mathrm{~mm}$ are reference values of $L, k_{g t}$, and $d$. By employing these parameters, we obtained the correlation:

$$
\varphi_{\infty}=0.043 L^{*}+0.004684 k^{*} / d^{*}+0.03109 L^{*} k^{*} / d^{*}+0.00214 .
$$

Table 2. Values of $\varphi_{\infty}$.

\begin{tabular}{|c|c|c|c|}
\hline$L(\mathrm{~m})$ & $d(\mathrm{~mm})$ & $k_{g t}(\mathrm{~W} /(\mathrm{mK}))$ & $\varphi_{\infty}$ \\
\hline \multirow{9}{*}{50} & \multirow{3}{*}{84} & 1.0 & 0.0359 \\
\hline & & 1.6 & 0.0453 \\
\hline & & 2.3 & 0.0532 \\
\hline & \multirow{3}{*}{94} & 1.0 & 0.0346 \\
\hline & & 1.6 & 0.0434 \\
\hline & & 2.3 & 0.0508 \\
\hline & \multirow{3}{*}{104} & 1.0 & 0.0339 \\
\hline & & 1.6 & 0.0419 \\
\hline & & 2.3 & 0.0487 \\
\hline \multirow{9}{*}{100} & \multirow{3}{*}{84} & 1.0 & 0.0700 \\
\hline & & 1.6 & 0.0884 \\
\hline & & 2.3 & 0.1035 \\
\hline & \multirow{3}{*}{94} & 1.0 & 0.0676 \\
\hline & & 1.6 & 0.0847 \\
\hline & & 2.3 & 0.0989 \\
\hline & \multirow{3}{*}{104} & 1.0 & 0.0662 \\
\hline & & 1.6 & 0.0817 \\
\hline & & 2.3 & 0.0950 \\
\hline \multirow{9}{*}{200} & \multirow{4}{*}{84} & 1.0 & 0.1315 \\
\hline & & 1.6 & 0.1644 \\
\hline & & 2.3 & 0.1910 \\
\hline & & 1.0 & 0.1270 \\
\hline & \multirow[t]{2}{*}{94} & 1.6 & 0.1575 \\
\hline & & 2.3 & 0.1827 \\
\hline & \multirow{3}{*}{104} & 1.0 & 0.1243 \\
\hline & & 1.6 & 0.1521 \\
\hline & & 2.3 & 0.1756 \\
\hline
\end{tabular}

Equation (11) can be employed to determine $\varphi_{\infty}$, and therefore $T_{\text {ave }}-T_{f m}$ and $T_{\text {out }}-T_{f m}$ in quasi-stationary regime, for every single U-tube borehole with $50 \mathrm{~m} \leq L \leq 200 \mathrm{~m}, 84 \mathrm{~mm} \leq d \leq 104 \mathrm{~mm}$, $1.0 \mathrm{~W} /(\mathrm{mK}) \leq k_{g t} \leq 2.3 \mathrm{~W} /(\mathrm{mK})$. The mean square deviation of the values of $\varphi_{\infty}$ given by Equation (11) from those reported in Table 2 is equal to 0.00237 , i.e., to $2.51 \%$ of the mean value of $\varphi_{\infty}$.

\subsection{Transient Regime}

The simulation results revealed that the time dependence of $\varphi$ during the two first working hours can be fitted by the equation:

$$
\varphi=\varphi_{\infty}\left(1+a \mathrm{e}^{-b t^{*}}\right),
$$

where $a$ and $b$ are dimensionless coefficients dependent on $L, d, k_{g t}$ and $\dot{V}$, and $t^{*}$ is the dimensionless time, evaluated as the working time $\tau$ divided by two hours. Moreover, the dependence on $L$ and $\dot{V}$ can be reduced to the dependence on the dimensionless parameter:

$$
V^{*}=\dot{V} /\left(\dot{V}_{o} L^{*}\right)
$$

Four values of $V^{*}$ were considered, namely $0.5,1,2$ and 4 . The coefficients $a$ and $b$ were determined by fitting values of $\varphi / \varphi_{\infty}$ as a function of $t^{*}$ obtained numerically. Figure 4 illustrates the best fit for $V^{*}$ 
$=1, d^{*}=1, k^{*}=1$, that was obtained through two simulations: with $L^{*}=1, \dot{V} / \dot{V}_{0}=1, d^{*}=1, k^{*}=1$, and with $L^{*}=2, \dot{V} / \dot{V}_{0}=2, d^{*}=1, k^{*}=1$. As shown by the figure, the best-fit curve yields very accurate values of $\varphi / \varphi_{\infty}$, except for $0.125<t^{*}<0.25$, where it slightly overestimates the simulation results.

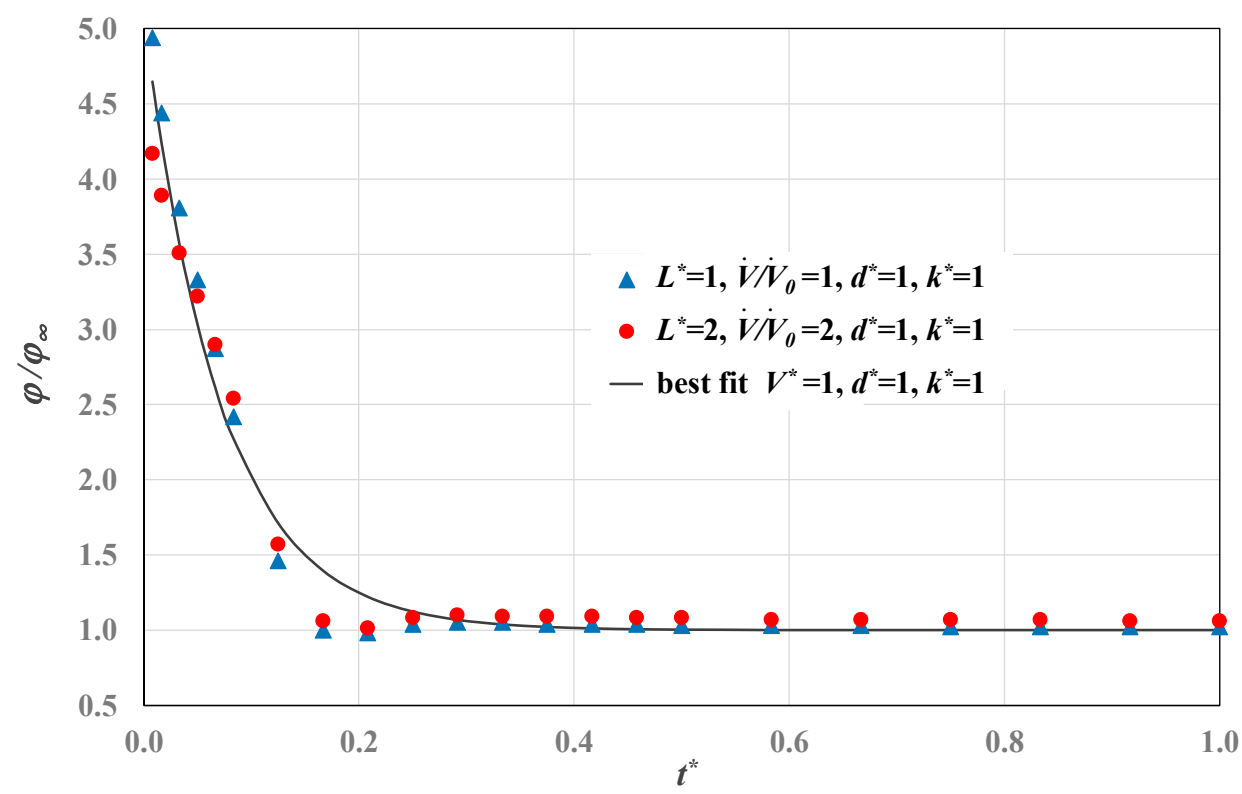

Figure 4. Best fit of the simulation results of $\varphi / \varphi_{\infty}$ versus $t^{*}$ for $V^{*}=1, d^{*}=1, k^{*}=1$.

The obtained values of $a$ and $b$ are listed in Table 3. As revealed by the table, $a$ depends on $V^{*}, d^{*}$, and $k^{*}$, while $b$ depends only on $V^{*}$. The correlation:

$$
\begin{aligned}
& a=\left(-0.0303 V^{* 2}+2.5926 V^{*}-0.47\right) d^{*}+\left(0.3423 V^{* 2}+2.4718 V^{*}-0.3486\right) k^{* 2} \\
& -\left(0.9892 V^{* 2}+7.744 V^{*}-1.0553\right) k^{*}+1.1697 V^{* 2}+8.7332 V^{*}-2.3034
\end{aligned}
$$

fits the values of $a$ given by Table 3 with a mean square deviation equal to 0.246 .

The relative discrepancy between Equation (14) and Table 3 can be considered as negligible for values of $a$ higher than 10 .

The coefficient $b$, which depends only on $V^{*}$, can be expressed as:

$$
b=0.6667 V^{* 2}+21.8 V^{*}-5.6667 .
$$

Equations (11), (12), (14) and (15) yield the time evolution of $\varphi$ during the first two working hours, for every single U-tube BHE, in any working condition.

After the first hour of operation, the ratio $\varphi / \varphi_{\infty}$ is very close to the asymptotic value 1 . By integrating Equation (12) between $t^{*}=0$ and $t^{*}=0.5$ one obtains the mean value of $\varphi$ during the first hour:

$$
\varphi_{\text {mean } 1}=\varphi_{\infty}\left[0.5+\frac{a}{b}\left(1-\mathrm{e}^{-0.5 b}\right)\right] .
$$


Table 3. Values of $a$ and $b$ to be used in Equation (12).

\begin{tabular}{|c|c|c|c|c|}
\hline$V^{*}$ & $d^{*}$ & $k^{*}$ & $a$ & $b$ \\
\hline \multirow{9}{*}{0.5} & \multirow{3}{*}{0.8936} & 0.625 & 1.8 & 7 \\
\hline & & 1 & 1.2 & 7 \\
\hline & & 1.4375 & 0.8 & 7 \\
\hline & \multirow{3}{*}{1} & 0.625 & 1.9 & 7 \\
\hline & & 1 & 1.3 & 7 \\
\hline & & 1.4375 & 0.9 & 7 \\
\hline & \multirow{3}{*}{1.1064} & 0.625 & 2 & 7 \\
\hline & & 1 & 1.4 & 7 \\
\hline & & 1.4375 & 1 & 7 \\
\hline \multirow{9}{*}{1} & \multirow{3}{*}{0.8936} & 0.625 & 5.2 & 14 \\
\hline & & 1 & 3.9 & 14 \\
\hline & & 1.4375 & 3.2 & 14 \\
\hline & \multirow{3}{*}{1} & 0.625 & 5.4 & 14 \\
\hline & & 1 & 4.1 & 14 \\
\hline & & 1.4375 & 3.4 & 14 \\
\hline & \multirow{3}{*}{1.1064} & 0.625 & 5.6 & 14 \\
\hline & & 1 & 4.3 & 14 \\
\hline & & 1.4375 & 3.6 & 14 \\
\hline \multirow{9}{*}{2} & \multirow{3}{*}{0.8936} & 0.625 & 15 & 42 \\
\hline & & 1 & 11.7 & 42 \\
\hline & & 1.4375 & 10 & 42 \\
\hline & \multirow{3}{*}{1} & 0.625 & 15.5 & 42 \\
\hline & & 1 & 12.2 & 42 \\
\hline & & 1.4375 & 10.5 & 42 \\
\hline & \multirow{3}{*}{1.1064} & 0.625 & 16 & 42 \\
\hline & & 1 & 12.7 & 42 \\
\hline & & 1.4375 & 11 & 42 \\
\hline \multirow{9}{*}{4} & \multirow{3}{*}{0.8936} & 0.625 & 37 & 92 \\
\hline & & 1 & 29 & 92 \\
\hline & & 1.4375 & 25 & 92 \\
\hline & \multirow{3}{*}{1} & 0.625 & 38 & 92 \\
\hline & & 1 & 30 & 92 \\
\hline & & 1.4375 & 26 & 92 \\
\hline & \multirow{3}{*}{1.1064} & 0.625 & 39 & 92 \\
\hline & & 1 & 31 & 92 \\
\hline & & 1.4375 & 27 & 92 \\
\hline
\end{tabular}

\section{Validation of the 3D Simulation Code}

The validation of the $3 \mathrm{D}$ simulation code has been performed by comparison between the time-dependent values of $T_{f m}$ evaluated through this code and those calculated analytically through the BHE model proposed by Man et al. [35]. The BHE selected for the comparison has $L=100 \mathrm{~m}, d=$ $94 \mathrm{~mm}, k_{g t}=1.6 \mathrm{~W} /(\mathrm{mK}),(\rho c)_{g t}=1.600 \mathrm{MJ} /\left(\mathrm{m}^{3} \mathrm{~K}\right)$, volume flow rate $18 \mathrm{~L} / \mathrm{min}$, is placed in a ground with $k_{g}=1.8 \mathrm{~W} /(\mathrm{mK})(\rho c)_{g}=2.500 \mathrm{MJ} /\left(\mathrm{m}^{3} \mathrm{~K}\right), T_{g}=14{ }^{\circ} \mathrm{C}$, and receives a time constant linear power of $60 \mathrm{~W} / \mathrm{m}$, i.e., to a total thermal power $\dot{Q}=6000 \mathrm{~W}$. The initial temperature coincides with $T_{g}(z)$ in the whole domain. The properties of water are evaluated at $20{ }^{\circ} \mathrm{C}$ and are [44] $\rho_{w}=998.21 \mathrm{~kg} / \mathrm{m}^{3}, \mu_{w}=$ $1.0016 \mathrm{mPa} \mathrm{s}, c_{p w}=4184.1 \mathrm{~J} /(\mathrm{kg} \mathrm{K}), k_{w}=0.59846 \mathrm{~W} /(\mathrm{mK})$. The convection coefficient, calculated by the Churchill correlation [45], is $h=1800.5 \mathrm{~W} /\left(\mathrm{m}^{2} \mathrm{~K}\right)$.

In the 3D simulation code, the condition of constant thermal power $\dot{Q}=6000 \mathrm{~W}$ has been implemented by imposing the constant value of $T_{\text {in }}-T_{\text {out }}$ given by Equation (3), namely $4.789{ }^{\circ} \mathrm{C}$. The mesh is that illustrated in Figure 2.

In the 2D axisymmetric BHE model proposed by Man et al. [35], the BHE is represented by a cylindrical surface with radius $r_{0}$ that releases a constant and uniform power per unit area corresponding 
to the total thermal power received by the BHE. The generating surface represents the fluid, and the borehole has the same properties as the ground. The analytical solution for the temperature field is determined by the Green's function method.

The mean temperature of the surface with radius $r_{0}$, that will be denoted by $T_{f m}$, is given by [35]:

$$
\begin{aligned}
& T_{f m}(\tau)=\frac{q_{l}}{8 \pi k_{g} L} \int_{0}^{L} \mathrm{~d} z \int_{0}^{\tau} d \tau^{\prime} \frac{1}{\tau-\tau^{\prime}} \times I_{0}\left[\frac{r_{0}^{2}}{2 \alpha_{g}\left(\tau-\tau^{\prime}\right)}\right] \times \operatorname{Exp}\left[-\frac{r_{0}^{2}}{2 \alpha_{g}\left(\tau-\tau^{\prime}\right)}\right] \\
& \times\left\{\operatorname{Erf}\left[\frac{L-z}{2 \sqrt{\alpha_{g}\left(\tau-\tau^{\prime}\right)}}\right]+2 \operatorname{Erf}\left[\frac{z}{2 \sqrt{\alpha_{g}\left(\tau-\tau^{\prime}\right)}}\right]-\operatorname{Erf}\left[\frac{L+z}{2 \sqrt{\alpha_{g}\left(\tau-\tau^{\prime}\right)}}\right]\right\}+T_{g}
\end{aligned}
$$

where $\alpha_{g}=\left(k_{g} /(\rho c)_{g}\right)$ is the thermal diffusivity of the ground, equal to $0.72 \times 10^{-6} \mathrm{~m}^{2} / \mathrm{s}$ in the case considered.

The value of $r_{0}$ to be employed in the model has been determined by imposing that the thermal resistance of the cylindrical layer between $r_{0}$ and the BHE radius is equal to the BHE thermal resistance. The latter has been determined through a stationary 2D finite element simulation of a borehole cross section that includes a ground layer having radius $2 \mathrm{~m}$ and an isothermal external surface. The temperature difference between the fluid and the external ground surface has been set equal to $25^{\circ} \mathrm{C}$ for one pipe and to $20^{\circ} \mathrm{C}$ for the other pipe. The convection coefficient is $h=1800.5 \mathrm{~W} /\left(\mathrm{m}^{2} \mathrm{~K}\right)$. We adopted a very fine mesh, composed of 139,008 triangular elements. A particular of the mesh employed is illustrated in Figure 5. The result is $R_{b}=0.09863 \mathrm{mK} / \mathrm{W}$ and, as a consequence, $r_{0}=2.491 \mathrm{~cm}$.

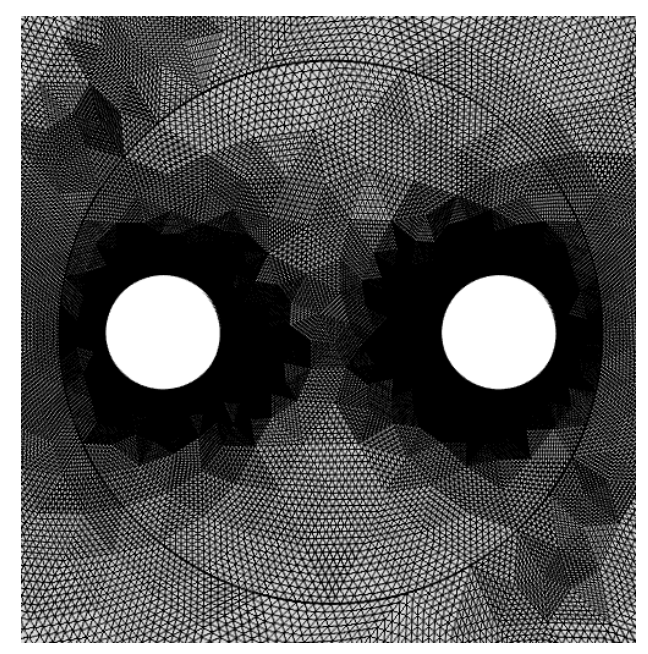

Figure 5. Particular of the mesh adopted to determine $R_{b}$, for the validation of the 3D simulation code. The boundary between the polyethylene pipes and the grout is hidden by the triangular elements.

The diagrams of $T_{f m}$ versus the decimal logarithm of time in hours obtained by the 3D finite element simulation and by the numerical integration of Equation (17) are compared in Figure 6, in the time range between $10^{-2} \mathrm{~h}$ and $10^{2} \mathrm{~h}$. The mean square deviation between the results of the finite element simulation and those obtained by the model by Man et al. [35] is $0.26^{\circ} \mathrm{C}$. The small discrepancies that occur from $10^{-2}$ to $10^{-1} \mathrm{~h}$ are very probably due to the non-perfect accuracy of the analytical model, that does not consider the exact total value and distribution of the BHE heat capacity. On the contrary, those occurring from 10 to $10^{2} \mathrm{~h}$ are probably due to numerical errors in the 3D simulation, that increase with time. 


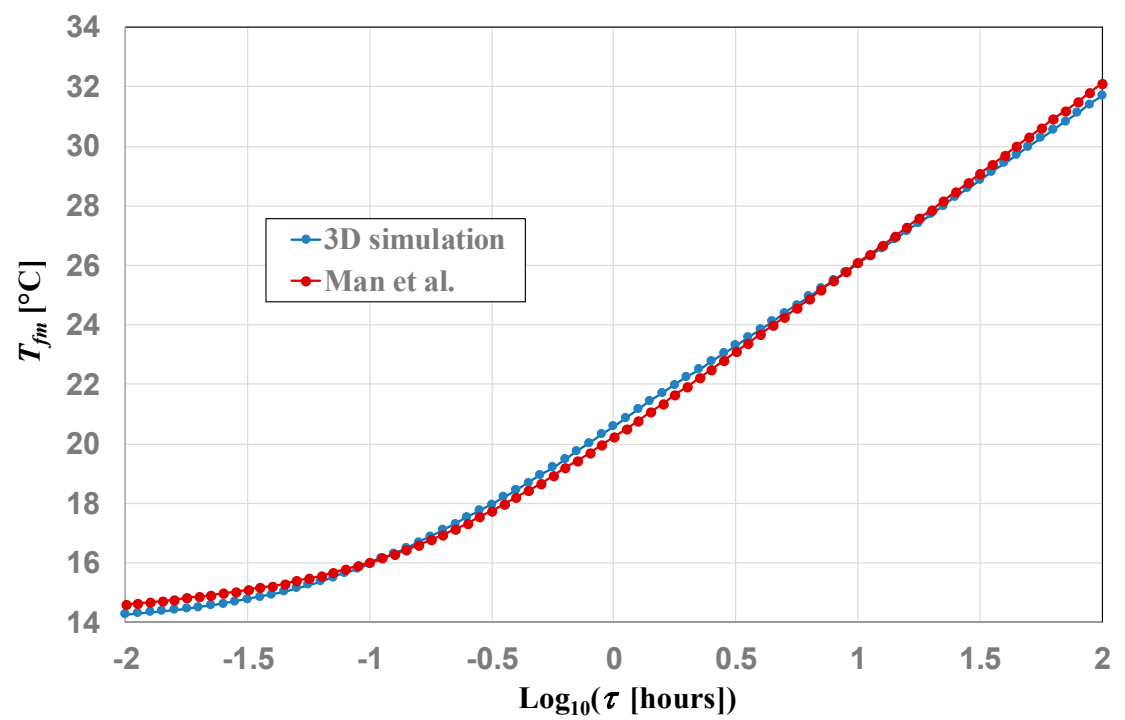

Figure 6. Comparison of the time evolution of $T_{f m}$ evaluated numerically and that determined through the analytical model by Man et al. [35].

\section{Validity of the Correlations for Other BHE Diameters, Thermal Conductivities of the Ground, Working Conditions}

Although the correlations for $\varphi$ reported in Section 3 were obtained by assuming $D_{b}=152 \mathrm{~mm}$, $k_{g}=1.8 \mathrm{~W} /(\mathrm{mK})$, and summer operation with constant $T_{i n}$, they hold also for other BHE diameters, ground thermal conductivities, and working conditions.

The applicability of the values of $\varphi_{\infty}$ reported in Table 2 to other borehole diameters is shown in Figure 7, that refers to BHEs with $L=100 \mathrm{~m}, d=84 \mathrm{~mm}, k_{g t}=1.0 \mathrm{~W} /(\mathrm{mK}), k_{g}=1.8 \mathrm{~W} /(\mathrm{mK}), \dot{V}=$ $12 \mathrm{~L} / \mathrm{min}$, and BHE diameters $134 \mathrm{~mm}$ and $170 \mathrm{~mm}$. Clearly, the value of $D_{b}$ has no effect on $\varphi$ if $k_{g t}$ $=k_{g}$. Therefore, the value $k_{g t}=1.0 \mathrm{~W} /(\mathrm{mK})$ has been selected, to analyze a critical condition, with a high ratio $k_{g} / k_{g t}$. Higher values of this ratio should be avoided. The diagrams of $T_{\text {ave }}-T_{f m}$ versus $\left(T_{\text {in }}-T_{\text {out }}\right) / \dot{V}$ obtained by the 3D simulations with these BHE diameters are compared with the line obtained by employing the value of $\varphi_{\infty}$ reported in Table 2, namely $\varphi_{\infty}=0.07$. The comparison shows the applicability of the correlation to other BHE diameters.

The applicability of the values of $\varphi_{\infty}$ reported in Table 2 to other ground thermal conductivities is shown in Figure 8, that refers to BHEs with $L=100 \mathrm{~m}, d=94 \mathrm{~mm}, k_{g t}=1.6 \mathrm{~W} /(\mathrm{mK}), \dot{V}=12 \mathrm{~L} / \mathrm{min}$, ground thermal conductivities 1.4 and $2.2 \mathrm{~W} /(\mathrm{mK})$. The diagrams of $T_{\text {ave }}-T_{\text {fm }}$ versus $\left(T_{\text {in }}-T_{\text {out }}\right) / \dot{V}$ obtained by the 3D simulations with $k_{g}=1.4$ and $2.2 \mathrm{~W} /(\mathrm{mK})$ are compared with the line obtained by employing the value of $\varphi_{\infty}$ listed in Table 2, namely $\varphi_{\infty}=0.0847$. The results reveal that the correlation can be applied to other values of the ground conductivity.

The applicability of the values of $\varphi_{\infty}$ reported in Table 2 to other working conditions is shown in Figure 9, that refers to thermal response tests (TRTs) performed on a borehole with $L=100 \mathrm{~m}, d=$ $94 \mathrm{~mm}, k_{g t}=1.6 \mathrm{~W} /(\mathrm{mK}), k_{g}=1.8 \mathrm{~W} /(\mathrm{mK})$. The working conditions are $\dot{V}=12 \mathrm{~L} / \mathrm{min}$ and $q_{l}=50 \mathrm{~W} / \mathrm{m}$ for the first TRT, $\dot{V}=18 \mathrm{~L} / \mathrm{min}$ and $q_{l}=60 \mathrm{~W} / \mathrm{m}$ for the second TRT, $\dot{V}=24 \mathrm{~L} / \mathrm{min}$ and $q_{l}=80 \mathrm{~W} / \mathrm{m}$ for the third TRT. In a TRT, $T_{\text {in }}-T_{\text {out }}$ is a constant and $T_{\text {ave }}-T_{f m}$ becomes constant after $2 \mathrm{~h}$. Therefore, only one value of $T_{\text {ave }}-T_{f m}$ as a function of $\left(T_{\text {in }}-T_{\text {out }}\right) / \dot{V}$ is obtained for each TRT, in the quasi-stationary regime. In Figure 9, the values of $T_{\text {ave }}-T_{f m}$ as a function of $\left(T_{\text {in }}-T_{\text {out }}\right) / \dot{V}$ obtained for the TRTs described above are compared with the line obtained by employing the value of $\varphi_{\infty}$ reported in Table 2 . The points that represent the results for the TRTs lay on the correlation line. 


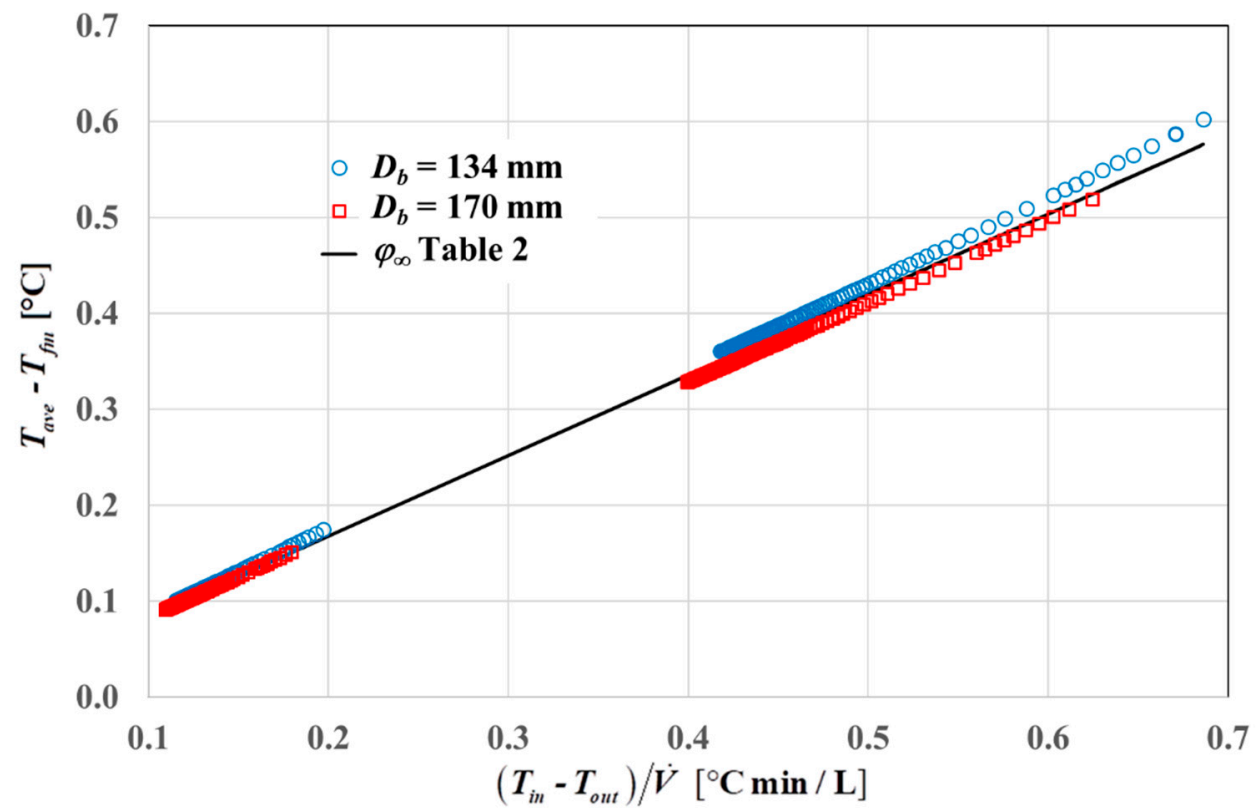

Figure 7. Diagrams of $T_{\text {ave }}-T_{f m}$ versus $\left(T_{\text {in }}-T_{\text {out }}\right) / \dot{V}$ obtained by 3D simulations, for $D_{b}=134 \mathrm{~mm}$ and $D_{b}=170 \mathrm{~mm}$, and by the value of $\varphi_{\infty}$ reported in Table 2 .

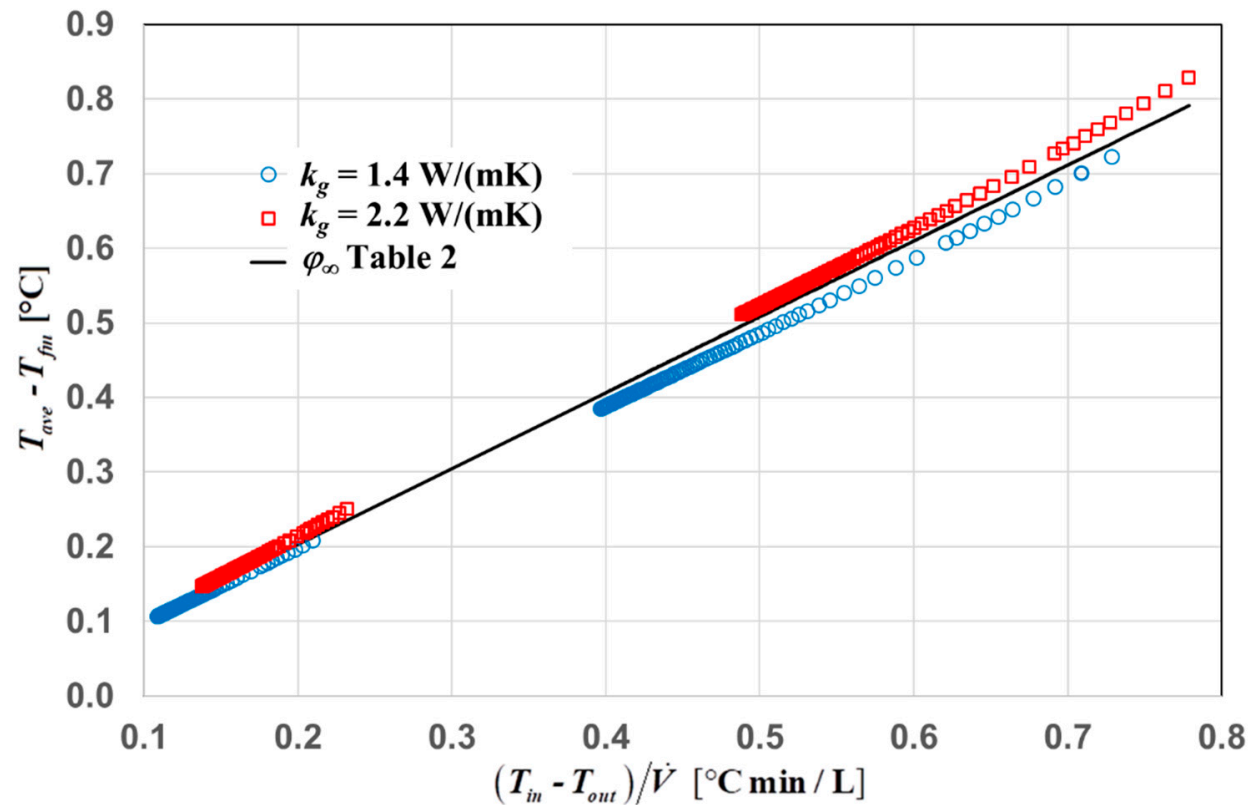

Figure 8. Diagrams of $T_{\text {ave }}-T_{f m}$ versus $\left(T_{\text {in }}-T_{\text {out }}\right) / \dot{V}$ obtained by 3D simulations, for $k_{g}=1.4 \mathrm{~W} /(\mathrm{mK})$ and $k_{g}=2.2 \mathrm{~W} /(\mathrm{mK})$, and by the value of $\varphi_{\infty}$ reported in Table 2 . 


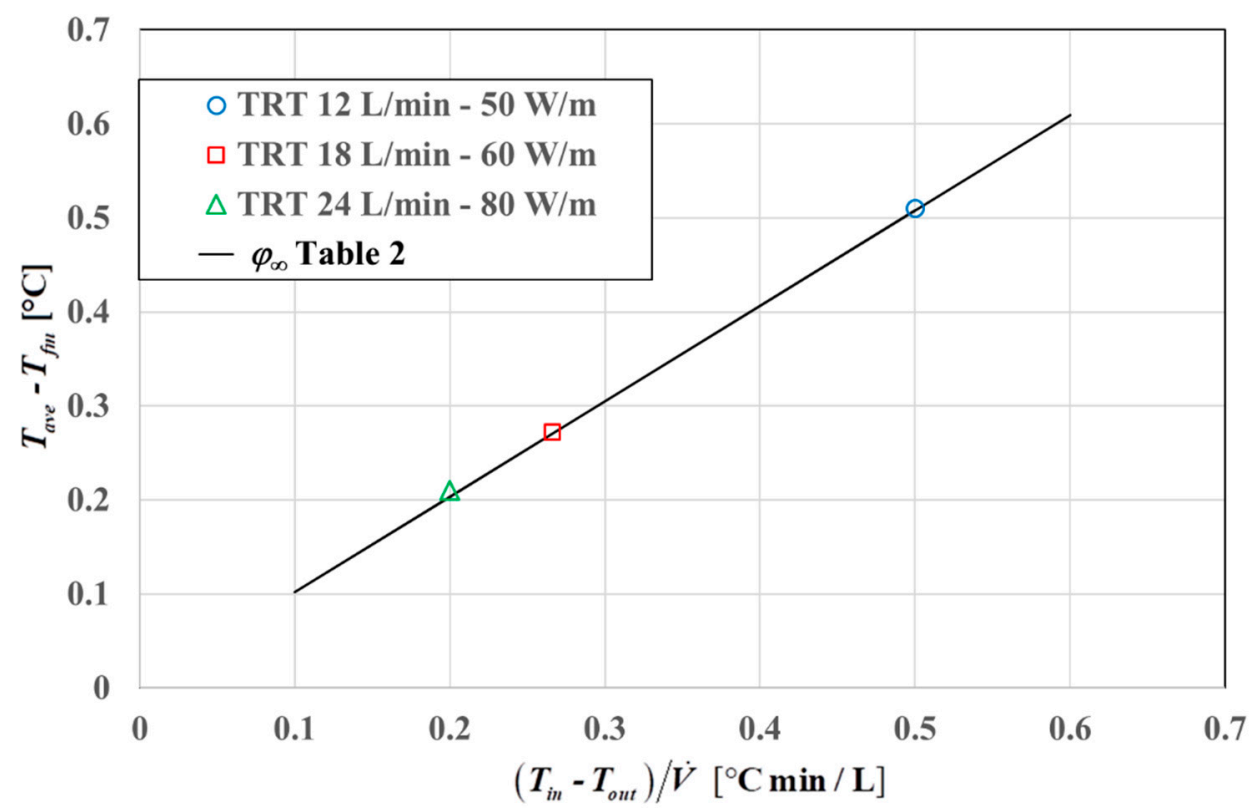

Figure 9. Values of $T_{\text {ave }}-T_{f m}$ versus $\left(T_{\text {in }}-T_{\text {out }}\right) / \dot{V}$ obtained for TRTs, compared with the correlation given by the value of $\varphi_{\infty}$ reported in Table 2 .

\section{Evaluation of the Time Evolution of $T_{\text {out }}$ by Means of the Correlations for $\varphi$}

In this section, we show how the correlations for $\varphi$ determined in Section 3 can be used to evaluate accurately $T_{\text {out }}$ by means of simulation codes that yield $T_{f m}$, first in the case of constant heat load and flow rate, then in the case of time dependent heat load and constant flow rate. The accuracy obtainable in working conditions with time dependent flow rate is not analyzed in this paper.

\subsection{Constant Heat Load}

In this example, we determine $T_{f m}$ by the analytical BHE model by Man et al. [35] and $T_{\text {out }}$ by the correlations for $\varphi$, and we point out the errors that occur in the short time if one employs simpler methods, such as the finite line-source (FLS) model combined with either $R_{b}$ or $R_{b e f f}$, or the model by Man et al. [35] without the correlations for $\varphi$.

Consider the same BHE as in Section $4\left(L=100 \mathrm{~m}, d=94 \mathrm{~mm}, k_{g t}=1.6 \mathrm{~W} /(\mathrm{mK}),(\rho c)_{g t}=\right.$ $\left.1.600 \mathrm{MJ} /\left(\mathrm{m}^{3} \mathrm{~K}\right), k_{g}=1.8 \mathrm{~W} /(\mathrm{mK})(\rho c)_{g}=2.500 \mathrm{MJ} /\left(\mathrm{m}^{3} \mathrm{~K}\right), T_{g}=14{ }^{\circ} \mathrm{C}\right)$, but with $\dot{V}=12 \mathrm{~L} / \mathrm{min}$ and $q_{l}=$ $50 \mathrm{~W} / \mathrm{m}$ (i.e., $\dot{Q}=5000 \mathrm{~W}$ ), as in the first TRT considered in Section 5 . The water properties have the same values as in Section 4. The convection coefficient is $h=1303.8 \mathrm{~W} /\left(\mathrm{m}^{2} \mathrm{~K}\right)$ [45]. The BHE thermal resistance, determined by a 2D steady state simulation by the method explained in Section 4 , is $R_{b}=$ $0.09965 \mathrm{mK} / \mathrm{W}$. The effective BHE thermal resistance has been determined by Hellström's analytical expression [47]:

$$
R_{b, e f f}=R_{b} \eta \operatorname{coth} \eta
$$

where:

$$
\eta=\frac{L}{\dot{m} c_{p} \sqrt{R_{a} R_{b}}}
$$

and $R_{a}$ is the internal resistance between the tubes. The latter has been evaluated through the expression [48]:

$$
R_{a}=\frac{2\left(T_{f 1}-T_{f 2}\right)}{q_{l 1}-q_{l 2}},
$$

where $T_{f 1}$ and $T_{f 2}$ are the bulk temperatures in the tubes, and $q_{l 1}$ and $q_{l 2}$ are the heat fluxes per unit length from the tubes. The results obtained are $R_{a}=0.47555 \mathrm{mK} / \mathrm{W}, R_{b, e f f}=0.10950 \mathrm{mK} / \mathrm{W}$. 
In the model of Ref. [35], the radius of the generating surface such that the thermal resistance of the cylindrical layer between that surface and the BHE radius equals $R_{b}$ is $r_{0}=2.462 \mathrm{~cm}$.

The simplest method to obtain the time evolution of $T_{\text {out }}$ is determining $T_{s m}$ by the FLS model and $T_{f m}$ by Equation (1), then adopting the approximation:

$$
T_{f m} \approx T_{a v e}
$$

and evaluating $T_{\text {out }}$ by the relation:

$$
T_{\text {out }}=T_{\text {ave }}-0.5 \frac{\dot{Q}}{\dot{m} c_{p}} .
$$

An improvement of this method is determining $T_{s m}$ by the FLS model, $T_{\text {ave }}$ by the definition of effective BHE thermal resistance:

$$
T_{\text {ave }}-T_{s m}=q_{l m} R_{b, e f f},
$$

and then $T_{\text {out }}$ by Equation (22). This improvement allows obtaining correct values of $T_{\text {out }}$ in the long term.

The time evolution of $T_{\text {out }}$ obtained by applying the FLS model and $R_{b}$ and that obtained by applying the FLS model and $R_{b, e f f}$ are compared in Figure 10 with that obtained by a 3D finite element simulation performed by the method described in Section 2 and the grid illustrated in Figure 2. The time interval considered is from $10^{-2} \mathrm{~h}$ to $10^{2} \mathrm{~h}$, in the logarithmic scale.

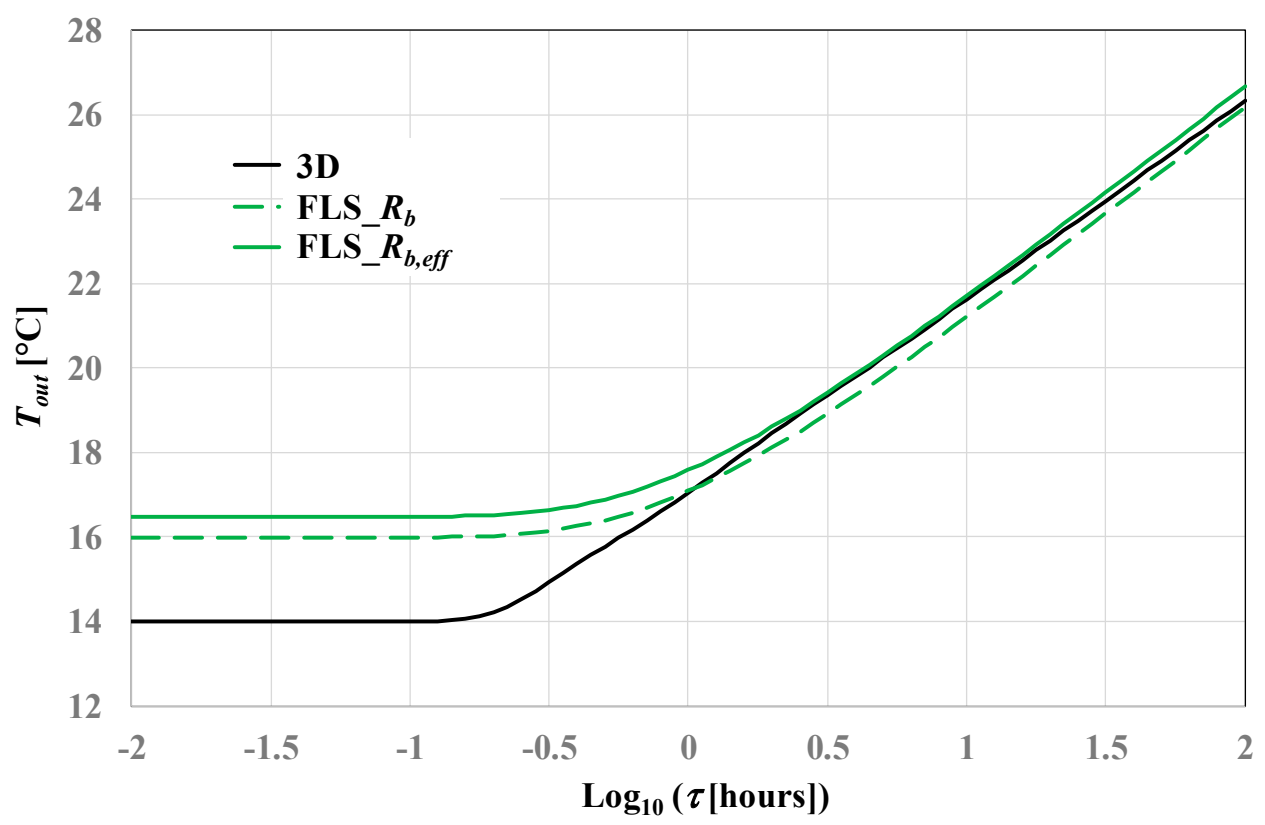

Figure 10. Time evolutions of $T_{\text {out }}$ obtained by a 3D numerical simulation (3D), by the FLS model and $R_{b}\left(\right.$ FLS_ $\left.R_{b}\right)$, and by the FLS model and $R_{b, \text { eff }}\left(\right.$ FLS_ $\left.R_{b, \text { eff }}\right)$ : constant heat load.

The time evolution of $T_{s m}$ by the FLS model has been obtained through the numerical integration of the expression determined by Bandos et al. [15]:

$$
T_{s m}(\tau)=\frac{q_{l}}{4 \pi k_{g}} \int_{r_{b} / \sqrt{4 \alpha_{g} \tau}}^{\infty}\left\{4 \operatorname{Erf}\left(\frac{L u}{r_{b}}\right)-2 \operatorname{Erf}\left(\frac{2 L u}{r_{b}}\right)-\left(3+\mathrm{e}^{-4 L^{2} u^{2} / r_{b}^{2}}-4 \mathrm{e}^{-L^{2} u^{2} / r_{b}^{2}}\right) \frac{r_{b}}{\sqrt{\pi} L u}\right\} \frac{\mathrm{e}^{-u^{2}}}{u} \mathrm{~d} u .
$$

The figure shows that the methods based on the FLS model yield an important overestimation of $T_{\text {out }}$ during the first hour. In fact, while the true value of $T_{\text {out }}$ remains practically equal to $14{ }^{\circ} \mathrm{C}$ during the first ten minutes, $T_{\text {out }}$ jumps immediately from 14 to $16{ }^{\circ} \mathrm{C}$ according to the FLS_ $R_{b}$ method, 
and from 14 to $16.48^{\circ} \mathrm{C}$ according to the FLS_ $R_{b, \text { eff }}$ method, that is more accurate in the long term. The overestimation of $T_{\text {out }}$ by the FLS_ $R_{b, \text { eff }}$ method starts decreasing after $10 \mathrm{~min}$, but remains relevant for about one hour $\left(0.76^{\circ} \mathrm{C}\right.$ for $\left.\tau=1 \mathrm{~h}\right)$.

A much more accurate evaluation of the time evolution of $T_{\text {out }}$ can be obtained by determining the time evolution of $T_{f m}$ by means of a full-time scale BHE model that takes into account the heat capacity of the borehole elements, and calculating $T_{\text {out }}$ through the coefficient $\varphi$ and Equation (6). The time evolution of $T_{\text {out }}$ yielded by the model of Ref. [35] and the coefficient $\varphi$ is compared with that obtained by the 3D finite element simulation described above in Figure 11. The time dependent value of $\varphi$ has been determined through Equation (12), with the value of $\varphi_{\infty}$ given in Table 2 (0.0847) and the values of $a$ and $b$ given in Table 3 (4.1 and 14, respectively). The figure shows that the combined use of the model by Man et al. [35] and of the coefficient $\varphi$ yields results in fair agreement with those of the 3D numerical simulation, even for very short times.

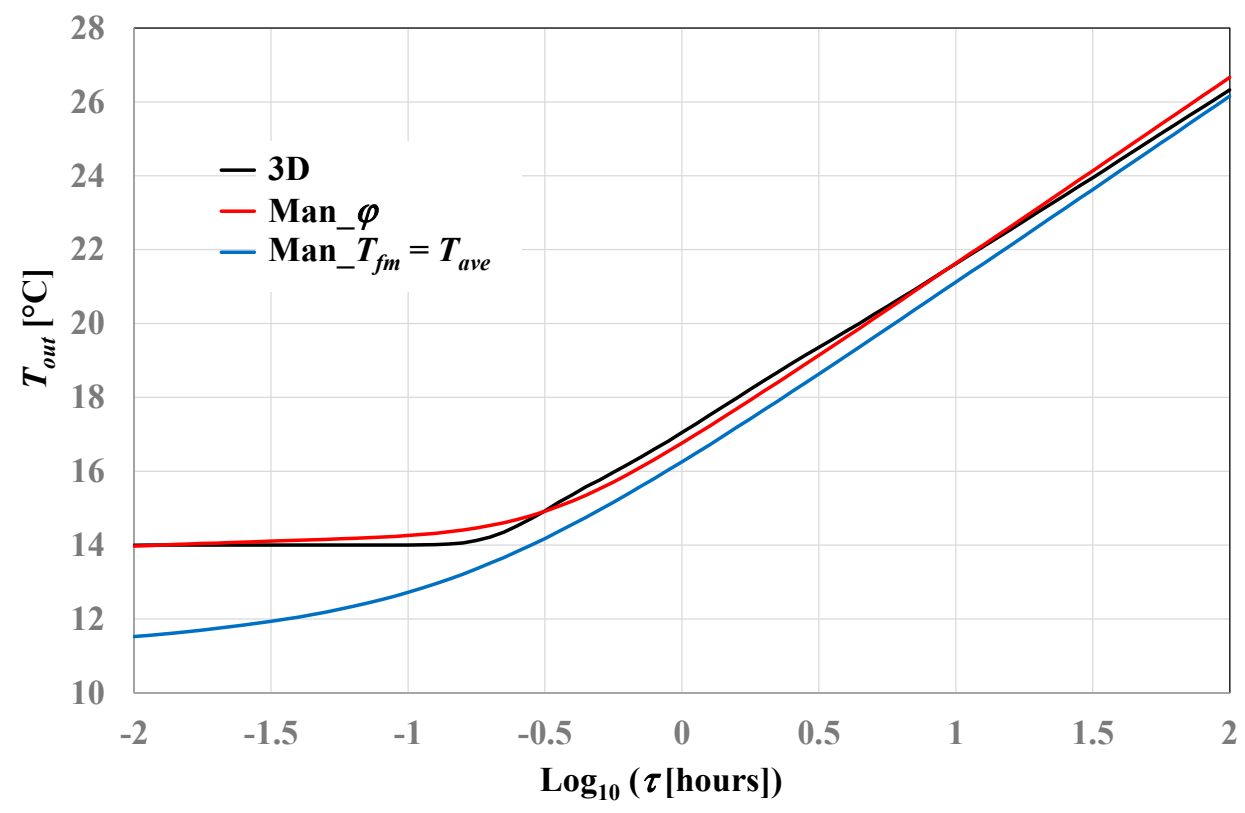

Figure 11. Time evolutions of $T_{\text {out }}$ obtained by a 3D numerical simulation (3D), by the model of Ref. [35] and our correlations for $\varphi\left(\operatorname{Man} \_\varphi\right)$, and by the model of Ref. [35] and the approximation $T_{f m}=T_{\text {ave }}$ $\left(\mathrm{Man} \_T_{f m}=T_{\text {ave }}\right)$ : constant heat load.

Figure 11 illustrates also the results obtained by employing the model of Ref. [35] coupled with the approximation $T_{f m} \approx T_{\text {ave }}$ and Equation (22), and shows that the approximate method underestimates $T_{\text {out }}$ in the short time.

\subsection{Time Dependent Heat Load}

We illustrate now the use of our correlation for $\varphi$ to determine $T_{\text {out }}$ in the case of a heat load with sharp step changes. We consider the hourly demand of thermal energy of an uninsulated office building located in Bologna (Italy), during the first two days of the heating period, namely October 15 and 16, of a typical meteorological year. The building has two floors and a heated floor area of $1255.7 \mathrm{~m}^{2}$. Heating is turned on at 5 a.m. and is turned off at 7 p.m. The hourly values of the thermal energy required by the building, including the distribution and emission heat losses, have been determined by a dynamic simulation performed through TRNSYS 17. In our example, we assume that the building is heated by a heat pump with $\mathrm{COP}=4$, coupled with 12 BHEs, each $100 \mathrm{~m}$ long, and determine the hourly heat loads on each BHE multiplying by 0.75 and dividing by 12 the hourly values of the total thermal energy required by the building. A dynamic simulation of the building-plant system with 
values of the heat pump COP determined at each hour is beyond the aims of this paper. The absolute values of the negative hourly heat load on each BHE are illustrated in Figure 12.

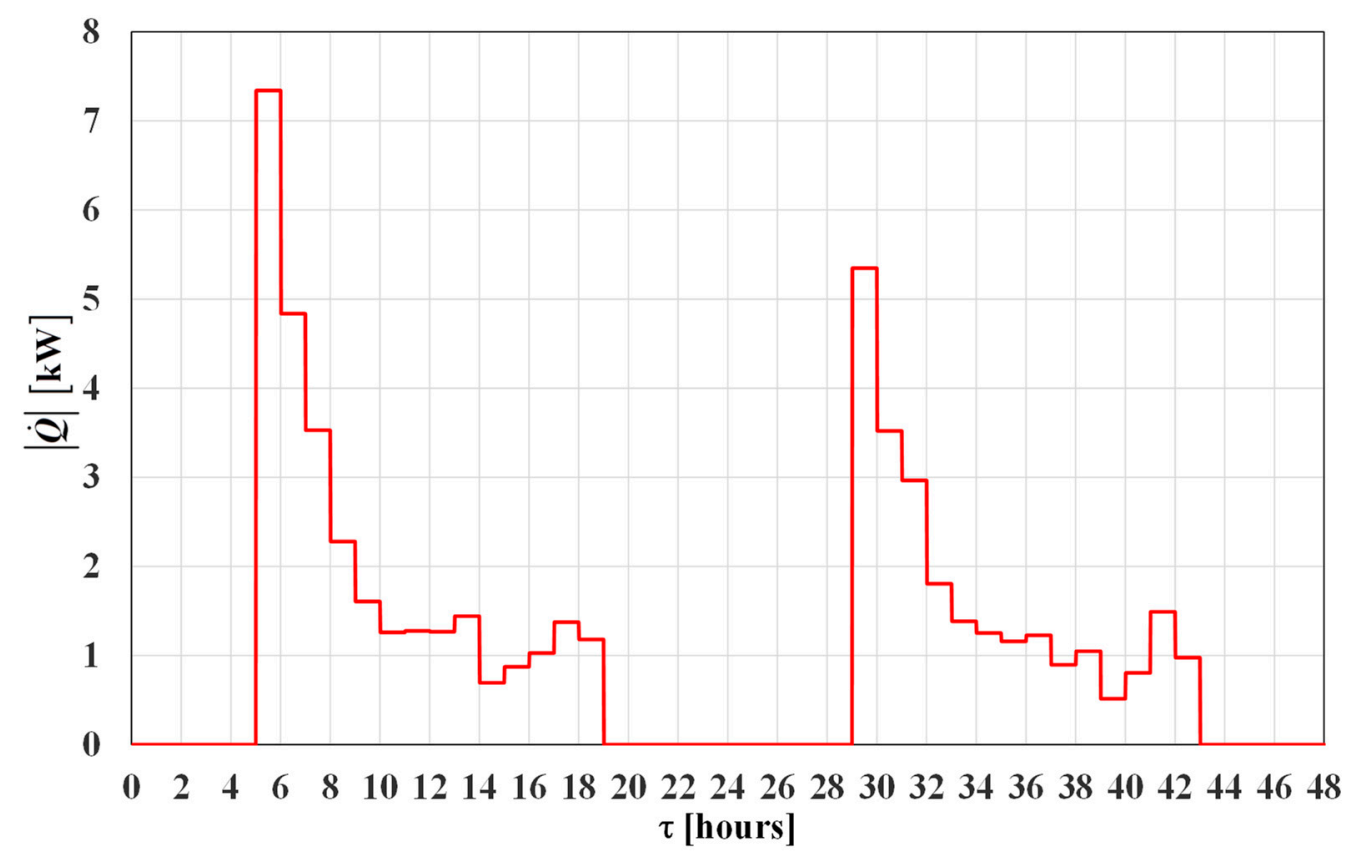

Figure 12. Absolute values of the hourly heat load on each $\mathrm{BHE}$, in $\mathrm{kW}$, corresponding to the heating demand of an office building in Bologna during October 15 and 16 of a typical meteorological year.

The absolute values of $\dot{Q}$ during the first five hours are 7.341, 4.835, 3.527, 2.278, $1.606 \mathrm{~kW}$, respectively, and the absolute value of the mean heat load during the first $24 \mathrm{~h}$ is $1.249 \mathrm{~kW}$. We consider the same BHE, the same flow rate, and the same initial and boundary conditions as in Section 6.1, with the only difference that the thermal properties of water are evaluated at $11{ }^{\circ} \mathrm{C}$, and are [44] $\rho_{w}$ $=999.61 \mathrm{~kg} / \mathrm{m}^{3}, \mu_{w}=1.2691 \mathrm{mPa} \mathrm{s}, c_{p w}=4193.6 \mathrm{~J} /(\mathrm{kg} \mathrm{K}), k_{w}=0.58193 \mathrm{~W} /(\mathrm{mK})$, and the convection coefficient is [45] $h=1172.3 \mathrm{~W} /\left(\mathrm{m}^{2} \mathrm{~K}\right)$.

The time evolutions of $T_{f m}$ and of $T_{\text {out }}$ are determined by a 3D finite element simulation of the BHE, performed by the same simulation code and the same mesh as in Section 6.1. Then, the time evolution of $T_{\text {out }}$ is calculated from that of $T_{f m}$ by means of our correlations for $\varphi$ and Equation (6), with the following method. The time interval $\Delta t$ needed by the fluid to go from the inlet to the outlet is evaluated by assuming plug flow, i.e., a uniform velocity in each cross section: $14 \mathrm{~min}$ for the case considered. For each hour, the dimensionless time $t^{*}$ of Equation (12) starts from zero at the beginning of the hour, and the application of the correlations for $\varphi$ starts after a time interval $\Delta t$ from the beginning of the hour. During the time interval $\Delta t$ of the first hour, $T_{\text {out }}$ is kept constant with the same value as in the initial instant, as is physically consistent and confirmed by the 3D simulation. During the time interval $\Delta t$ of any other hour, $T_{\text {out }}$ is considered as linearly varying with time from the last time instant of the preceding hour to the first time instant after $\Delta t$ of that hour. A comparison between the time evolution of $T_{\text {out }}$ yielded by the 3D simulation and that obtained through our correlation for $\varphi$ is illustrated in Figure 13, and a particular for the first five hours is illustrated in Figure 14. The figures report also the time evolution of $T_{\text {out }}$ that is obtained by employing the same method to manage the initial time interval $\Delta t$ of each hour, and by applying the customary approximation $T_{f m}=T_{\text {ave }}$ instead of the correlations for $\varphi$. 


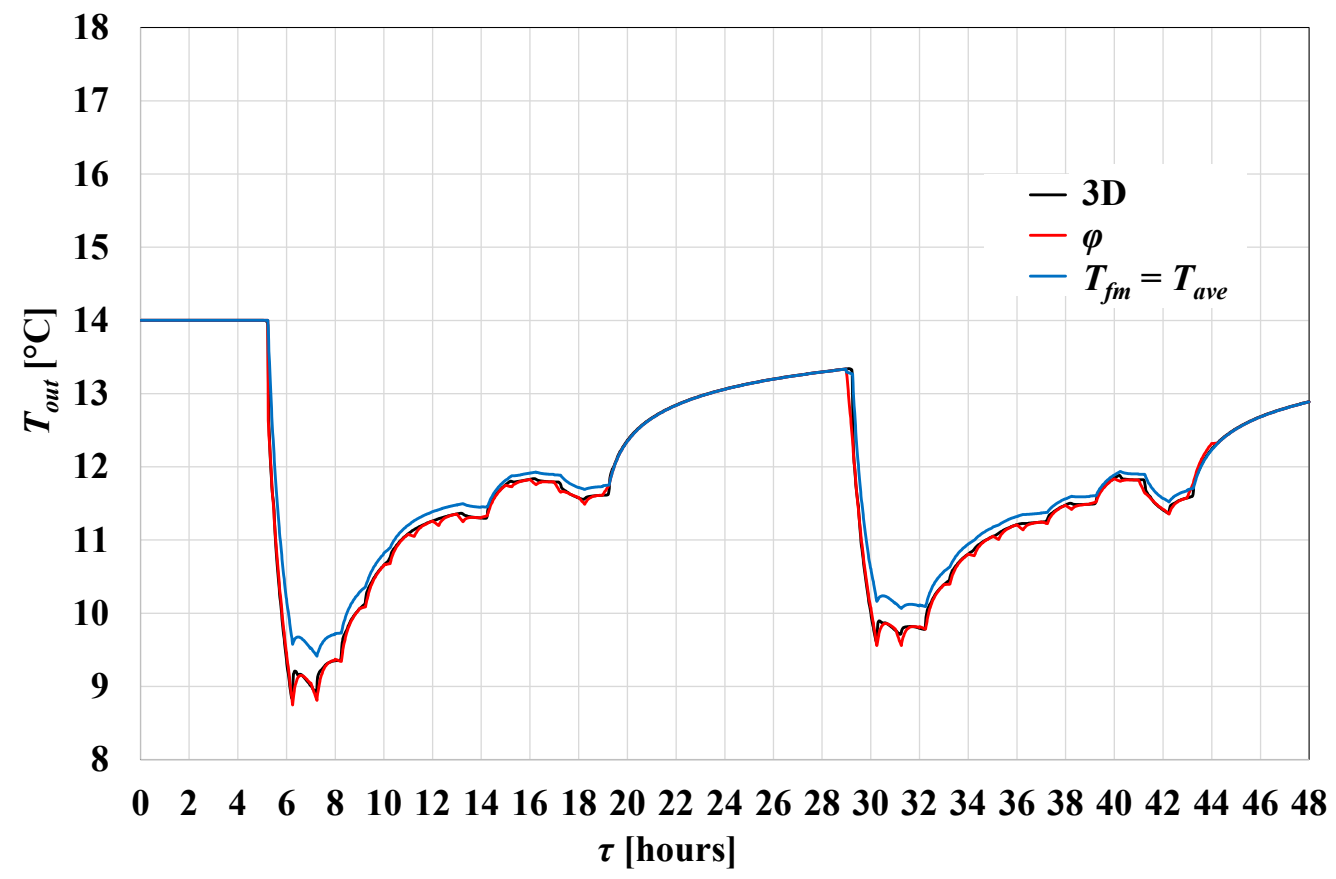

Figure 13. Time evolutions of $T_{\text {out }}$ obtained by a 3D numerical simulation (3D), by $T_{f m}$ and our correlations for $\varphi(\varphi)$, and by $T_{f m}$ and the approximation $T_{f m}=T_{\text {ave }}\left(T_{f m}=T_{\text {ave }}\right)$ : time dependent heat load.

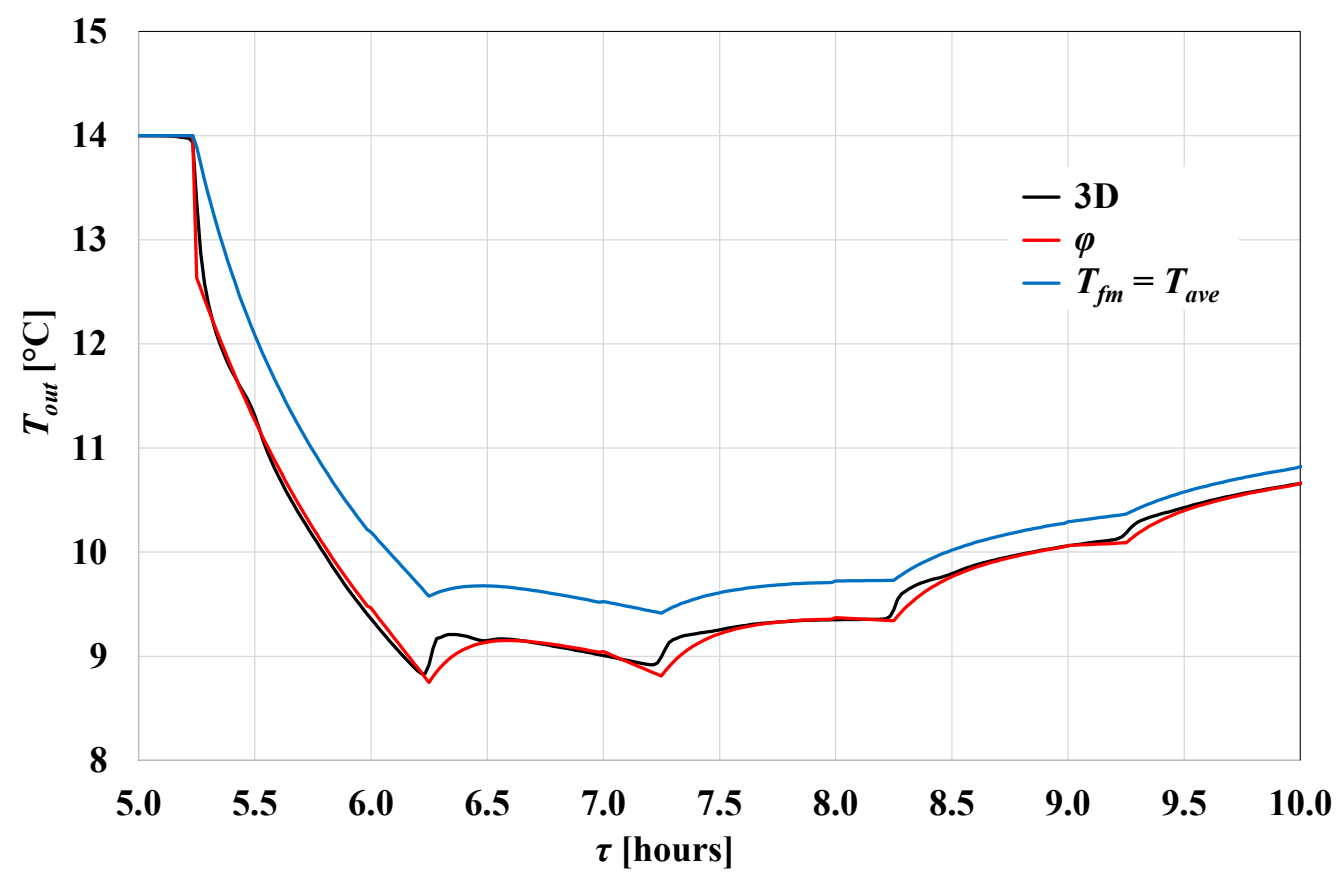

Figure 14. Time evolutions of $T_{\text {out }}$ obtained by a 3D numerical simulation (3D), by $T_{f m}$ and our correlations for $\varphi(\varphi)$, and by $T_{f m}$ and the approximation $T_{f m}=T_{\text {ave }}\left(T_{f m}=T_{\text {ave }}\right)$ : time dependent heat load, first $5 \mathrm{~h}$.

The figures show that the time evolution of $T_{\text {out }}$ obtained by applying the correlations for $\varphi$ is much more accurate, especially during the most critical hours. The mean square deviation from the results of the $3 \mathrm{D}$ simulation, during the first three hours, is $0.1{ }^{\circ} \mathrm{C}$ for the method employing our correlations for $\varphi$ and $0.6{ }^{\circ} \mathrm{C}$ for that employing the approximation $T_{f m}=T_{\text {ave }}$. 


\section{Calculation of $\boldsymbol{R}_{\boldsymbol{b}, \text { eff }}$ Through $\varphi_{\infty}$}

In this section we show that, in quasi-stationary working conditions, the effective BHE thermal resistance, $R_{b, e f f}$, can be easily calculated by means of the dimensionless coefficient $\varphi_{\infty}$. Then, we compare the values of $R_{b, \text { eff }}$ evaluated through our general correlation for $\varphi_{\infty}$, given by Equation (11), with those determined by 3D finite element computations and by Hellström's analytical solution.

One can rewrite Equation (23) as:

$$
R_{b, e f f}=\frac{T_{a v e}-T_{s m}}{q_{l m}}=\frac{T_{a v e}-T_{f m}}{q_{l m}}+\frac{T_{f m}-T_{s m}}{q_{l m}}=\frac{T_{a v e}-T_{f m}}{q_{l m}}+R_{b} .
$$

In quasi-stationary working conditions, the energy balance of the fluid yields:

$$
q_{l m}=\frac{\dot{m} c_{p}\left(T_{\text {in }}-T_{\text {out }}\right)}{L} .
$$

By substituting Equation (26) in Equation (25), one gets:

$$
R_{b, e f f}=R_{b}+\frac{T_{\text {ave }}-T_{f m}}{T_{\text {in }}-T_{\text {out }}} \frac{L}{\dot{m} c_{p}} .
$$

In quasi-stationary conditions, Equation (5) yields:

$$
\frac{T_{\text {ave }}-T_{f m}}{T_{\text {in }}-T_{\text {out }}}=\frac{\dot{V}_{0}}{\dot{V}} \varphi_{\infty} .
$$

By substituting Equation (28) in Equation (27), one obtains:

$$
R_{b, e f f}=R_{b}+\frac{\dot{V}_{0}}{\dot{V}} \frac{\varphi_{\infty} L}{\dot{m} c_{p}} .
$$

Equations (29) and (11) allow a very simple calculation of the difference between $R_{b, \text { eff }}$ and $R_{b}$, for single U-tube BHEs. Equation (29) can be employed also in combination with Equation (27) of Ref. [43], for double U-tube BHEs. The BHE thermal resistance $R_{b}$ can be calculated either by employing a suitable approximate expression, or, more accurately, through a 2D numerical simulation of a borehole cross section.

A comparison between the values of $R_{b, \text { eff }}$ obtained by Equations (29) and (11), denoted by $R_{b, e f f, \varphi}$, those evaluated through 3D numerical computations, denoted by $R_{b, e f f, 3 \mathrm{D}}$, and those obtained by Equations (18) and (19), denoted by $R_{b, e f f, H}$, is illustrated in Table 4, for single U-tube BHEs having $L$ $=100 \mathrm{~m}$ or $200 \mathrm{~m}, D_{b}=152 \mathrm{~mm}, k_{g}=1.8 \mathrm{~W} /(\mathrm{mK}), \dot{V}=12 \mathrm{~L} / \mathrm{min}$ and inlet temperature $T_{\text {in }}=32{ }^{\circ} \mathrm{C}$. The convection coefficient is $h=1462.2 \mathrm{~W} /\left(\mathrm{m}^{2} \mathrm{~K}\right)$, as indicated in Table 1 . The values of $R_{a}$ and of $R_{b}$ to be employed in Equations (18) and (19) have been determined by performing stationary 2D numerical simulations of a borehole cross section with the method described in Section 4 and evaluating $R_{a}$ with Equation (20).

The table shows that the values of $R_{b, \text { eff }}$ evaluated through our correlation for $\varphi_{\infty}$ are in fair agreement both with those computed directly by $3 \mathrm{D}$ numerical computations and with those yielded by Hellström's analytical method. The highest percent deviation from $R_{b, e f f, 3 \mathrm{D}}$ is $-1.46 \%$ for $R_{b, e f f, \varphi}$ and $-1.81 \%$ for $R_{b, e f f, H}$; the mean square deviation from $R_{b, e f f, 3 \mathrm{D}}$ is $0.00093 \mathrm{mK} / \mathrm{W}$ for $R_{b, e f f, \varphi}$ and $0.00119 \mathrm{mK} / \mathrm{W}$ for $R_{b, e f f, H}$.

The values of $R_{b, e f f, \varphi}$ reported in Table 4 have been determined by calculating $\varphi_{\infty}$ through Equation (11). If one employs the values of $\varphi_{\infty}$ reported in Table 2, the highest percent deviation from $R_{b, e f f, 3 \mathrm{D}}$ reduces to $-1.05 \%$ and the mean square deviation reduces to $0.00086 \mathrm{mK} / \mathrm{W}$. 
Table 4. Values of $R_{b, e f f, \varphi}, R_{b, e f f, 3 \mathrm{D}}$, and $R_{b, e f f, H}$, for $D_{b}=152 \mathrm{~mm}, k_{g}=1.8 \mathrm{~W} /(\mathrm{mK}), T_{i n}=32{ }^{\circ} \mathrm{C}, \dot{V}=$ $12 \mathrm{~L} / \mathrm{min}$, and different values of $d, L$ and $k_{g t}$.

\begin{tabular}{|c|c|c|c|c|c|}
\hline$d(\mathrm{~mm})$ & $L(\mathrm{~m})$ & $k_{g t}(\mathrm{~W} /(\mathrm{mK}))$ & $R_{b, e f f, \varphi}(\mathrm{mK} / \mathrm{W})$ & $R_{b, e f f, 3 \mathrm{D}}(\mathrm{mK} / \mathrm{W})$ & $R_{b, e f f, H}(\mathrm{mK} / \mathrm{W})$ \\
\hline \multirow{6}{*}{84} & \multirow{3}{*}{100} & 1.0 & 0.1469 & 0.1472 & 0.1467 \\
\hline & & 1.6 & 0.1152 & 0.1159 & 0.1154 \\
\hline & & 2.3 & 0.0998 & 0.1001 & 0.0995 \\
\hline & \multirow{3}{*}{200} & 1.0 & 0.1709 & 0.1711 & 0.1705 \\
\hline & & 1.6 & 0.1442 & 0.1457 & 0.1444 \\
\hline & & 2.3 & 0.1345 & 0.1348 & 0.1324 \\
\hline \multirow{6}{*}{94} & \multirow{3}{*}{100} & 1.0 & 0.1364 & 0.1368 & 0.1362 \\
\hline & & 1.6 & 0.1090 & 0.1097 & 0.1092 \\
\hline & & 2.3 & 0.0953 & 0.0958 & 0.0953 \\
\hline & \multirow{3}{*}{200} & 1.0 & 0.1595 & 0.1598 & 0.1592 \\
\hline & & 1.6 & 0.1365 & 0.1382 & 0.1369 \\
\hline & & 2.3 & 0.1280 & 0.1289 & 0.1267 \\
\hline \multirow{6}{*}{104} & \multirow{3}{*}{100} & 1.0 & 0.1260 & 0.1267 & 0.1260 \\
\hline & & 1.6 & 0.1033 & 0.1041 & 0.1036 \\
\hline & & 2.3 & 0.0916 & 0.0922 & 0.0916 \\
\hline & \multirow{3}{*}{200} & 1.0 & 0.1484 & 0.1491 & 0.1483 \\
\hline & & 1.6 & 0.1297 & 0.1316 & 0.1303 \\
\hline & & 2.3 & 0.1226 & 0.1240 & 0.1217 \\
\hline
\end{tabular}

\section{Conclusions}

By means of 3D finite element simulations of single U-tube borehole heat exchangers (BHEs), we have obtained simple expressions of a dimensionless coefficient $\varphi$ that yields two temperature differences: that between the average of inlet and outlet fluid temperature, $T_{\text {avee }}$, and the mean fluid temperature, $T_{f m}$; that between the outlet temperature, $T_{\text {out }}$, and $T_{f m}$. The obtained expressions of $\varphi$ hold for single U-tube BHEs with any diameter between 130 and $170 \mathrm{~mm}$, any shank spacing compatible with the diameter, and any BHE length between $50 \mathrm{~m}$ and $200 \mathrm{~m}$, both in quasi-stationary and in transient regime. The 3D simulation code has been validated by comparing the time evolution of $T_{f m}$ obtained by the code with that obtained by applying an analytical BHE model.

We have shown that the obtained expressions of $\varphi$ allow an accurate evaluation of the time evolution of $T_{\text {out }}$ through a BHE model that yields the time evolution of $T_{f m}$, for working conditions with constant flow rate and either constant or time dependent heat load. Moreover, we have illustrated the errors that occur in the short time if one applies the finite line-source model coupled with the effective BHE thermal resistance, and those that occur if one applies a BHE model that yields $T_{f m}$ coupled with the approximation $T_{f m}=T_{\text {ave }}$. Thus, the obtained expressions of $\varphi$ are a useful complement of the BHE models that yield $T_{f m}$. Finally, we have shown that the obtained quasi-stationary values of $\varphi$ can be used for a simple evaluation of the effective BHE thermal resistance.

Author Contributions: Conceptualization, E.Z.; methodology, A.J., C.N. and E.Z.; software, A.J., C.N. and E.Z.; validation, A.J., C.N. and E.Z.; formal analysis, A.J., C.N. and E.Z.; investigation, A.J., C.N. and E.Z.; data curation, A.J., C.N. and E.Z.; writing-original draft preparation, A.J., C.N. and E.Z.; writing-review and editing, A.J., C.N. and E.Z.; visualization, A.J., C.N. and E.Z.; supervision, E.Z. All authors have read and agree to the published version of the manuscript.

Funding: This research received no external funding.

Conflicts of Interest: The authors declare no conflict of interest. 


\section{Nomenclature}

\begin{tabular}{|c|c|}
\hline$a, b$ & dimensionless coefficients, defined in Equation (12) \\
\hline$c$ & rescaling coefficient \\
\hline$c_{p}$ & specific heat capacity at constant pressure $\left(\mathrm{J} \mathrm{kg}^{-1} \mathrm{~K}^{-1}\right)$ \\
\hline$d$ & shank spacing $(\mathrm{m})$ \\
\hline$d^{*}$ & $=d / d_{0}$, dimensionless shank spacing \\
\hline$D$ & diameter $(\mathrm{m})$ \\
\hline Erf & error function \\
\hline$f$ & dimensionless parameter defined in Equation (2) \\
\hline$h$ & convection coefficient $\left(\mathrm{W} \mathrm{m}{ }^{-2} \mathrm{~K}^{-1}\right)$ \\
\hline$k$ & thermal conductivity $\left(\mathrm{W} \mathrm{m}^{-1} \mathrm{~K}^{-1}\right)$ \\
\hline$k^{*}$ & $=k_{g t} / k_{g t 0}$, dimensionless thermal conductivity of grout \\
\hline$\widetilde{k}$ & $=k / c^{2}$, reduced thermal conductivity $\left(\mathrm{W} \mathrm{m}^{-1} \mathrm{~K}^{-1}\right)$ \\
\hline$L$ & BHE length $(\mathrm{m})$ \\
\hline$L^{*}$ & $=L / L_{0}$, dimensionless BHE length \\
\hline$\dot{m}$ & mass flow rate $\left(\mathrm{kg} \mathrm{s}^{-1}\right)$ \\
\hline$N u$ & Nusselt number \\
\hline$p$ & real coefficient \\
\hline $\operatorname{Pr}$ & Prandtl number \\
\hline$\dot{Q}$ & total heat flux $(\mathrm{W})$ \\
\hline$q_{l}$ & heat flux per unit length $\left(\mathrm{W} \mathrm{m}^{-1}\right)$ \\
\hline$R$ & thermal resistance per unit length $\left(\mathrm{m} \mathrm{K} \mathrm{W}^{-1}\right)$ \\
\hline$r$ & radius $(\mathrm{m})$ \\
\hline $\operatorname{Re}$ & Reynolds number \\
\hline$T$ & temperature $(\mathrm{K})$ \\
\hline$t^{*}$ & dimensionless time \\
\hline$u$ & integration variable \\
\hline$\dot{V}$ & volume flow rate $\left(\mathrm{m}^{3} \mathrm{~s}^{-1}\right)$ \\
\hline$V^{*}$ & dimensionless parameter defined in Equation (13) \\
\hline$w$ & fluid velocity $\left(\mathrm{m} \mathrm{s}^{-1}\right)$ \\
\hline$\widetilde{w}$ & $=w / c$, reduced fluid velocity $\left(\mathrm{m} \mathrm{s}^{-1}\right)$ \\
\hline$x, y$ & horizontal coordinates $(\mathrm{m})$ \\
\hline$z$ & vertical coordinate $(\mathrm{m})$ \\
\hline$\widetilde{z}$ & $=z / c$, reduced vertical coordinate $(\mathrm{m})$ \\
\hline
\end{tabular}

\section{Greek Symbols}

$\alpha$
$\eta$
$\mu$
$\rho$
$(\rho c)$
$\tau$
$\varphi$

thermal diffusivity $\left(\mathrm{m}^{2} \mathrm{~s}^{-1}\right)$

dimensionless parameter, defined in Equation (19)

dynamic viscosity (Pa s)

density $\left(\mathrm{kg} \mathrm{m}^{-3}\right)$

specific heat capacity per unit volume $\left(\mathrm{J} \mathrm{m}^{-3} \mathrm{~K}^{-1}\right)$

time (s)

dimensionless parameter, defined in Equation (5) 


\section{Subscripts}

0

1

2

3D

$\infty$

$a$

ave

$b$

$e$

eff

$f$

$g$

$g t$

H

i

in

$m$

mean 1

out

$p$

s

w

$x, y, z$

$\varphi$ reference, of the heat generating surface

of pipe 1

of pipe 2

obtained by 3D simulations

quasi-stationary regime

between the tubes

average

of the borehole heat exchanger

external

effective

of fluid

of ground

of grout

obtained by Hellström's method

internal

inlet

mean

mean value during the first hour

outlet

of polyethylene, of pipe

of the BHE surface

of water

in direction $x, y, z$

obtained through the coefficient $\varphi$

\section{References}

1. Lund, J.W.; Boyd, T.L. Direct Utilization of Geothermal Energy 2015 worldwide review. Geothermics 2016, 60, 66-93. [CrossRef]

2. Spitler, J.D.; Gehlin, S. Measured Performance of a Mixed-Use Commercial-Building Ground Source Heat Pump System in Sweden. Energies 2019, 12, 2020. [CrossRef]

3. Li, M.; Zhou, C.; Rao, Z. Hourly 50-year simulations of ground-coupled heat pumps using high-resolution analytical models. Energy Convers. Manag. 2019, 193, 15-24. [CrossRef]

4. Rivoire, M.; Casasso, A.; Piga, B.; Sethi, R. Assessment of Energetic, Economic and Environmental Performance of Ground-Coupled Heat Pumps. Energies 2018, 11, 1941. [CrossRef]

5. Naldi, C.; Zanchini, E. Effects of the total borehole length and of the heat pump inverter on the performance of a ground-coupled heat pump system. Appl. Therm. Eng. 2018, 128, 306-319. [CrossRef]

6. Ruiz-Calvo, F.; Montagud, C.; Cazorla-Marín, A.; Corberán, J.M. Development and Experimental Validation of a TRNSYS Dynamic Tool for Design and Energy Optimization of Ground Source Heat Pump Systems. Energies 2017, 10, 1510. [CrossRef]

7. Jung, Y.-J.; Kim, H.-J.; Choi, B.-E.; Jo, J.-H.; Cho, Y.-H. A Study on the Efficiency Improvement of Multi-Geothermal Heat Pump Systems in Korea Using Coefficient of Performance. Energies 2016, 9, 356. [CrossRef]

8. Kavanaugh, S.P.; Rafferty, K. Ground-Source Heat Pumps. Design of Geothermal Systems for Commercial and Institutional Buildings; ASHRAE: Atlanta, GA, USA, 1997.

9. Hellström, G.; Sanner, B. EED—Earth Energy Designer, Version 1.0, User's Manual; Knoblich \& Partner GmbH: Wetzlar, Germany, 1997.

10. Spitler, J.D. GLHEPRO-A design tool for commercial building ground loop heat exchanger. In Proceedings of the 4th International Conference on Heat Pumps in Cold Climates, Aylmer, QC, Canada, 17-18 August 2000; pp. 1-16. 
11. Fisher, D.E.; Rees, S.J.; Padhmanabhanc, S.K.; Murugappan, A. Implementation and validation of ground-source heat pump system models in an integrated building and system simulation environment. HvacR Res. 2006, 12, 693-710. [CrossRef]

12. ASHRAE Handbook, HVAC Applications; ASHRAE: Atlanta, GA, USA, 2015; Chapter 34.

13. Claesson, J.; Eskilson, P. Conductive Heat Extraction by a Deep Borehole, Analytical Studies; Technical Report; Lund University: Lund, Sweden, 1987.

14. Zeng, H.Y.; Diao, N.R.; Fang, Z.H. A finite line-source model for boreholes in geothermal heat exchangers. Heat Transf. Asian Res. 2002, 31, 558-567. [CrossRef]

15. Bandos, T.V.; Montero, A.; Fernandez, E.; Santander, J.L.G.; Isidro, J.M.; Perez, J.; Fernandez de Cordoba, P.J.; Urchueguia, J.F. Finite line-source model for borehole heat exchangers: Effect of vertical temperature variations. Geothermics 2009, 38, 263-270. [CrossRef]

16. Zanchini, E.; Lazzari, S. Temperature distribution in a field of long borehole heat exchangers (BHEs) subjected to a monthly averaged heat flux. Energy 2013, 59, 570-580. [CrossRef]

17. Puttige, A.R.; Rodriguez, J.; Monzó, P.; Cerdeira, F.; Fernandez, A.; Novelle, L.; Acuña, J.; Mogensen, P. Improvements on a Numerical Model of Borehole Heat Exchangers; European Geothermal Congress: Strasbourg, France, 2016; p. 10.

18. Cimmino, M.; Bernier, M. A semi-analytical method to generate g-functions for geothermal bore fields. Int. J. Heat Mass Transf. 2014, 70, 641-650. [CrossRef]

19. Monzó, P.; Mogensen, P.; Acuña, J.; Ruiz-Calvo, F.; Montagud, C. A novel numerical approach for imposing a temperature boundary condition at the borehole wall in borehole fields. Geothermics 2015, 56, 35-44. [CrossRef]

20. Priarone, A.; Fossa, M. Temperature response factors at different boundary conditions for modelling the single borehole heat exchanger. Appl. Therm. Eng. 2016, 103, 934-944. [CrossRef]

21. Naldi, C.; Zanchini, E. A new numerical method to determine isothermal g-functions of borehole heat exchanger fields. Geothermics 2019, 77, 278-287. [CrossRef]

22. Cimmino, M. The effects of borehole thermal resistances and fluid flow rate on the g-functions of geothermal bore fields. Int. J. Heat Mass Transf. 2015, 91, 1119-1127. [CrossRef]

23. Monzó, P.; Puttige, A.R.; Acuña, J.; Mogensen, P.; Cazorla, A.; Rodriguez, J.; Montagud, C.; Cerdeira, F. Numerical modeling of ground thermal response with borehole heat exchangers connected in parallel. Energy Build. 2018, 172, 371-384. [CrossRef]

24. De Carli, M.; Tonon, M.; Zarrella, A.; Zecchin, R. A computational capacity resistance model (CaRM) for vertical ground-coupled heat exchangers. Renew. Energy 2010, 35, 1537-1550. [CrossRef]

25. Zarrella, A.; Scarpa, M.; De Carli, M. Short time step analysis of vertical ground-coupled heat exchangers: The approach of CaRM. Renew. Energy 2011, 36, 2357-2367. [CrossRef]

26. Quaggiotto, D.; Zarrella, A.; Emmi, G.; De Carli, M.; Pockelé, L.; Vercruysse, J.; Psyk, M.; Righini, D.; Galgaro, A.; Mendrinos, D.; et al. Simulation-Based Comparison Between the Thermal Behavior of Coaxial and Double U-Tube Borehole Heat Exchangers. Energies 2019, 12, 2321. [CrossRef]

27. Bauer, D.; Heidemann, W.; Muller-Steinhagen, H.; Diersch, H.-J.G. Thermal resistance and capacity models for borehole heat exchangers. Int. J. Energy Res. 2011, 35, 312-320. [CrossRef]

28. Pasquier, P.; Marcotte, D. Short-term simulation of ground heat exchanger with an improved TRCM. Renew. Energy 2012, 46, 92-99. [CrossRef]

29. Ruiz-Calvo, F.; De Rosa, M.; Acuña, J.; Corberán, J.M.; Montagud, C. Experimental validation of a short-term Borehole-to-Ground (B2G) dynamic model. Appl. Energy 2015, 140, 210-223. [CrossRef]

30. Li, M.; Lai, A.C.K. New temperature response functions (G functions) for pile and borehole ground heat exchangers based on composite-medium line-source theory. Energy 2012, 38, 255-263. [CrossRef]

31. Li, M.; Lai, A.C.K. Analytical model for short-time responses of ground heat exchangers with U-shaped tubes: Model development and validation. Appl. Energy 2013, 104, 510-516. [CrossRef]

32. Zhang, L.; Zhang, Q.; Huang, G. A transient quasi-3D entire time scale line source model for the fluid and ground temperature prediction of vertical ground heat exchangers (GHEs). Appl. Energy 2016, 170, 65-75. [CrossRef]

33. Beier, R.A.; Smith, M.D. Minimum duration of in-situ tests on vertical boreholes. ASHRAE Trans. 2003, 109, 475-486. 
34. Xu, X.; Spitler, J.D. Modeling of vertical ground loop heat exchangers with variable convective resistance and thermal mass of the fluid. In Proceedings of the 10th International Conference on Thermal Energy Storage, Ecostock 2006, Pomona, NJ, USA, 31 May-2 June 2006.

35. Man, Y.; Yang, H.; Diao, N.; Liu, J.; Fang, Z. A new model and analytical solutions for borehole and pile ground heat exchangers. Int. J. Heat Mass Transf. 2010, 53, 2593-2601. [CrossRef]

36. Bandyopadhyay, G.; Gosnold, W.; Mann, M. Analytical and semi-analytical solutions for short-time transient response of ground heat exchangers. Energy Build. 2008, 40, 1816-1824. [CrossRef]

37. Javed, S.; Claesson, J. New analytical and numerical solutions for the short-term analysis of vertical ground heat exchangers. ASHRAE Trans. 2011, 117, 3-12.

38. Claesson, J.; Javed, S. An analytical method to calculate borehole fluid temperatures for time-scales from minutes to decades. ASHRAE Trans. 2011, 117, 279-288.

39. Beier, R.A. Transient heat transfer in a U-tube borehole heat exchanger. Appl. Therm. Eng. 2014, 62, $256-266$. [CrossRef]

40. Lamarche, L. Short-time analysis of vertical boreholes, new analytic solutions and choice of equivalent radius. Int. J. Heat Mass Transf. 2015, 91, 800-807. [CrossRef]

41. Naldi, C.; Zanchini, E. Full-Time-Scale Fluid-to-Ground Thermal Response of a Borefield with Uniform Fluid Temperature. Energies 2019, 12, 3750. [CrossRef]

42. Beier, R.A.; Spitler, J.D. Weighted average of inlet and outlet temperatures in borehole heat exchangers. Appl. Energy 2016, 174, 118-129. [CrossRef]

43. Zanchini, E.; Jahanbin, A. Simple equations to evaluate the mean fluid temperature of double U-tube borehole heat exchangers. Appl. Energy 2018, 231, 320-330. [CrossRef]

44. NIST Chemistry WebBook. Available online: https://webbook.nist.gov/chemistry/fluid/ (accessed on 18 December 2019).

45. Churchill, S.W. Comprehensive correlating equations for heat, mass and momentum transfer in fully developed flow in smooth tubes. Ind. Eng. Chem. Fundam. 1977, 16, 109-116. [CrossRef]

46. Zanchini, E.; Lazzari, S.; Priarone, A. Improving the thermal performance of coaxial borehole heat exchangers. Energy 2010, 35, 657-666. [CrossRef]

47. Hellström, G. Ground Heat Storage; Thermal Analysis of Duct Storage Systems. Ph.D. Thesis, Department of Mathematical Physics, University of Lund, Lund, Sweden, 1991.

48. Lamarche, L.; Kajl, S.; Beauchamp, B. A review of methods to evaluate borehole thermal resistances in geothermal heat-pump systems. Geothermics 2010, 39, 187-200. [CrossRef] 